\title{
The WACMOS-ET project - Part 2: Evaluation of global terrestrial evaporation data sets
}

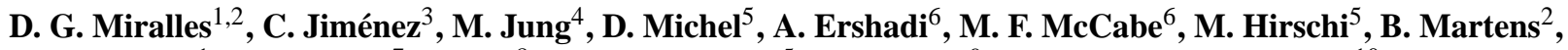 \\ A. J. Dolman ${ }^{1}$, J. B. Fisher ${ }^{7}$, Q. Mu ${ }^{8}$, S. I. Seneviratne ${ }^{5}$, E. F. Wood ${ }^{9}$, and D. Fernández-Prieto ${ }^{10}$ \\ ${ }^{1}$ Department of Earth Sciences, VU University Amsterdam, Amsterdam, the Netherlands \\ ${ }^{2}$ Laboratory of Hydrology and Water Management, Ghent University, Ghent, Belgium \\ ${ }^{3}$ Estellus, Paris, France \\ ${ }^{4}$ Max Planck Institute for Biogeochemistry, Jena, Germany \\ ${ }^{5}$ Institute for Atmospheric and Climate Science, ETH Zurich, Zurich, Switzerland \\ ${ }^{6}$ Division of Biological and Environmental Sciences and Engineering, King Abdullah University of Science and Technology, \\ Thuwal, Saudi Arabia \\ ${ }^{7}$ Jet Propulsion Laboratory, California Institute of Technology, Pasadena, California, USA \\ ${ }^{8}$ Department of Ecosystem and Conservation Sciences, University of Montana, Missoula, Montana, USA \\ ${ }^{9}$ Department of Civil and Environmental Engineering, Princeton University, Princeton, New Jersey, USA \\ ${ }^{10}$ ESRIN, European Space Agency, Frascati, Italy
}

Correspondence to: D. G. Miralles (diego.miralles@vu.nl)

Received: 1 October 2015 - Published in Hydrol. Earth Syst. Sci. Discuss.: 19 October 2015

Revised: 7 January 2016 - Accepted: 2 February 2016 - Published: 23 February 2016

\begin{abstract}
The WAter Cycle Multi-mission Observation Strategy - EvapoTranspiration (WACMOS-ET) project aims to advance the development of land evaporation estimates on global and regional scales. Its main objective is the derivation, validation, and intercomparison of a group of existing evaporation retrieval algorithms driven by a common forcing data set. Three commonly used process-based evaporation methodologies are evaluated: the PenmanMonteith algorithm behind the official Moderate Resolution Imaging Spectroradiometer (MODIS) evaporation product (PM-MOD), the Global Land Evaporation Amsterdam Model (GLEAM), and the Priestley-Taylor Jet Propulsion Laboratory model (PT-JPL). The resulting global spatiotemporal variability of evaporation, the closure of regional water budgets, and the discrete estimation of land evaporation components or sources (i.e. transpiration, interception loss, and direct soil evaporation) are investigated using river discharge data, independent global evaporation data sets and results from previous studies. In a companion article (Part 1), Michel et al. (2016) inspect the performance of these three models at local scales using measurements from eddy-covariance towers and include in the assessment the Surface Energy Bal-
\end{abstract}

ance System (SEBS) model. In agreement with Part 1, our results indicate that the Priestley and Taylor products (PT-JPL and GLEAM) perform best overall for most ecosystems and climate regimes. While all three evaporation products adequately represent the expected average geographical patterns and seasonality, there is a tendency in PM-MOD to underestimate the flux in the tropics and subtropics. Overall, results from GLEAM and PT-JPL appear more realistic when compared to surface water balances from 837 globally distributed catchments and to separate evaporation estimates from ERAInterim and the model tree ensemble (MTE). Nonetheless, all products show large dissimilarities during conditions of water stress and drought and deficiencies in the way evaporation is partitioned into its different components. This observed inter-product variability, even when common forcing is used, suggests that caution is necessary in applying a single data set for large-scale studies in isolation. A general finding that different models perform better under different conditions highlights the potential for considering biome- or climatespecific composites of models. Nevertheless, the generation of a multi-product ensemble, with weighting based on validation analyses and uncertainty assessments, is proposed as the 
best way forward in our long-term goal to develop a robust observational benchmark data set of continental evaporation.

\section{Introduction}

The importance of terrestrial evaporation (or "evapotranspiration") for hydrology, agriculture, and meteorology has long been recognized. In fact, most of our current understanding of the physics of evaporation originated in early experiments during the past 2 centuries (e.g. Dalton, 1802; Horton, 1919; Penman, 1948). However, it has been during the last decade that the interest of the scientific community in land evaporation has increased more dramatically, following the recognition of the key role it plays in climate (Wang and Dickinson, 2012; Dolman et al., 2014). Evaporation is highly sensitive to radiative forcing: changes in atmospheric chemical composition affect the magnitude of the flux, ensuring the propagation of anthropogenic impacts to all the components of the hydrological cycle (Wild and Liepert, 2010) and altering the global availability of water resources (Hagemann et al., 2013). In addition, evaporation regulates climate through a series of feedbacks acting on air temperature, humidity, and precipitation (Koster et al., 2006; Seneviratne et al., 2010), thus affecting climate trends (Douville et al., 2013; Sheffield et al., 2012) and hydro-meteorological extremes (Seneviratne et al., 2006; Teuling et al., 2013; Miralles et al., 2014a). Finally, due to the link between transpiration and photosynthesis, atmospheric carbon concentrations and carbon cycle feedbacks are closely linked to terrestrial evaporation (Reichstein et al., 2013). When these factors are taken together, evaporation represents a crucial nexus of processes and cycles in the climate system.

The rising interest of the climate community has coincided with an unprecedented availability of global field data to scrutinize the response of evaporation to climate impacts and feedbacks. However, due to the limitations in coverage of direct in situ measurements, the scientific community have turned to satellite remote sensing (Kalma et al., 2008; Wang and Dickinson, 2012; Dolman et al., 2014). Consequently, different international activities now focus on the joint advancement of remote sensing technology and evaporation science; these activities include the National Aeronautics and Space Administration (NASA) Energy and Water cycle Study (NEWS, http://nasa-news.org), the European Union WATer and global CHange (WATCH, http://www. eu-watch.org) project, and the Global Energy and Watercycle Experiment (GEWEX) LandFlux initiative (https:// hydrology.kaust.edu.sa/Pages/GEWEX_Landflux.aspx). Despite continuing progress in satellite and computing science, to date, the evaporative flux cannot be directly sensed from space; technology thus lags behind our physical knowledge of evaporation. Nonetheless, taking advantage of this existing knowledge, different models have been proposed to com- bine the physical variables that are linked to the evaporation process and can be observed from space (e.g. radiation, temperature, soil moisture, or vegetation dynamics). Such efforts have yielded a number of global evaporation products in recent years (Mu et al., 2007; Zhang et al., 2010; Fisher et al., 2008; Miralles et al., 2011b; Jung et al., 2010). These data sets are not to be interpreted as the direct result of satellite observations but rather as model outputs generated based on satellite forcing data. The reader is directed to Su et al. (2011) or McCabe et al. (2013) for recent reviews of the state of the art.

Despite the recent initiatives dedicated to exploring these evaporation data sets - LandFlux-EVAL in particular (Jiménez et al. (2011); Mueller et al. (2011, 2013) - the relative merits of each model on the global scale remain largely unexplored. To date, the lack of inter-model consistency in the choice of forcing data has hampered the attribution of the observed skill of each evaporation data set to differences in the models. Only recently, some efforts have been directed towards homogenizing the forcing of these models to allow the assessment of algorithm quality (Vinukollu et al., 2011a; Ershadi et al., 2014; Chen et al., 2014; McCabe et al., 2016). In 2012, the European Space Agency (ESA) WAter Cycle Multi-mission Observation Strategy - EvapoTranspiration (WACMOS-ET) project (http://WACMOSET.estellus. eu) started in response to the need for a thorough and consistent model intercomparison at different spatial and temporal scales. At the same time, WACMOS-ET is a direct contribution to GEWEX LandFlux, sharing the long-term goal of achieving global closure of surface water and energy budgets. The project objectives strive to (a) develop a reference input data set consisting of satellite observations, reanalysis data and in situ measured meteorology, (b) run a group of selected evaporation models forced by the reference input data set, and (c) perform a cross comparison, evaluation, and validation exercise of the evaporation data sets that result from running this group of models. Four algorithms that are commonly used by the research community have been tested: the Surface Energy Balance Model (SEBS; Su, 2002); the Penman-Monteith approach that sets the basis for the official Moderate Resolution Imaging Spectroradiometer (MODIS) evaporation product, hereafter referred to as PM-MOD $(\mathrm{Mu}$ et al., 2007, 2011, 2013); the Global Land Evaporation Amsterdam Model, GLEAM (Miralles et al., 2011b); and the Priestley and Taylor model from the Jet Propulsion Laboratory, PT-JPL (Fisher et al., 2008).

In a companion article - henceforth referred to as Part 1 - Michel et al. (2016) describe the results of the local validation activities of WACMOS-ET based on in situ evaporation measurements from eddy-covariance towers. Here, we present the global-scale inter-product evaluation. After forcing the models with the reference input data set (see Sect. 2.2 for the description of the forcing data), the resulting evaporation data sets are evaluated by means of (a) a general exploration of the global magnitude and spatiotemporal variability 
Table 1. Inputs from the reference input data set used in each of the models. The specific products chosen for each variable are also noted.

\begin{tabular}{llccc}
\hline Input & Product & PM-MOD & GLEAM & PT-JPL \\
\hline Radiation & SRB 3.1 & $\sqrt{ }$ & $\sqrt{ }$ & $\sqrt{ }$ \\
Air temperature & ERA-Interim & - & $\sqrt{ }$ & $\sqrt{ }$ \\
Precipitation & CFSR-Land & - & $\sqrt{ }$ & - \\
Soil moisture & CCI WACMOS & - & - & $\sqrt{ }$ \\
Air humidity & ERA-Interim & $\sqrt{ }$ & $\sqrt{ }$ & - \\
Snow cover & GlobSnow, NSIDC & - & $\sqrt{ }$ & $\sqrt{ }$ \\
$\begin{array}{l}\text { Vegetation } \\
\text { characteristics }\end{array}$ & Internally produced (except for the vegetation optical depth & from AMSR-E, see Sect. 2.2 and Part 1) & $\sqrt{ }$ & $\sqrt{ }$ \\
\hline
\end{tabular}

of the estimates (Sects. 3.1 and 3.2), (b) a comparison with other, commonly used, evaporation data sets (Sects. 3.1, 3.2, and 3.3), including the model tree ensemble (MTE) estimates by Jung et al. $(2009,2010)$ and the European Centre for Medium-range Weather Forecasts (ECMWF) Re-Analysis (ERA)-Interim (Dee et al., 2011), (c) an assessment of the skill to close the surface water balance over a broad range of catchments worldwide (Sect. 3.3), and (d) an analysis of the contribution to total terrestrial evaporation from the discrete components or sources of this flux, i.e. transpiration, interception loss, and direct evaporation from the soil (Sect. 3.4). Due to the difficulties that arise from executing SEBS on the global scale (see Su et al., 2010), the current work concentrates on PM-MOD, GLEAM, and PT-JPL, while the localscale analysis in Part 1 also includes the SEBS model.

\section{Methods and data}

\subsection{Models or algorithms}

Here we present a brief description of the three models that are studied in this article. For more exhaustive descriptions the reader is directed to Part 1 and to the original articles describing the parameterizations and algorithms of PM-MOD (Mu et al., 2007, 2011), GLEAM (Miralles et al., 2011b), and PT-JPL (Fisher et al., 2008). A summary of the forcing requirements of PM-MOD, GLEAM, and PT-JPL can be found in Table 1, together with the specific product for each input variable.

\subsubsection{PM-MOD}

The Penman-Monteith model by Mu et al. $(2007,2011)$ is arguably the most widely used remote-sensing-based global evaporation model, and, in its latest version, it is also the algorithm behind the official MODIS (MOD16) product (Mu et al., 2013). PM-MOD is based on the Monteith (1965) adaptation of Penman (1948); thus, it is has relatively high demands in terms of inputs. The parameterizations of aerodynamic and surface resistances for each component of evaporation are based on extending biome-specific conductance parameters to the canopy scale using vegetation phenology and meteorological data. The model applies the surface resistance scheme by Cleugh et al. (2007) - which uses leaf area index as suggested by Jarvis (1976) - in an extended version that considers the constraints of vapour pressure deficit and minimum temperature on stomatal conductance (Mu et al., 2007). However, in contrast to the majority of PenmanMonteith-type models, PM-MOD does not require soil moisture or wind speed data to parameterize the surface and aerodynamic resistances. The non-consideration of wind speed appears as an advantage when aiming for a fully observationdriven product. Snow sublimation and open-water evaporation are not considered independently of other processes. Unlike GLEAM and PT-JPL, which do not require calibration, the resistance parameters in PM-MOD have been calibrated with data from a set of global eddy-covariance towers (see Mu et al., 2011).

\subsubsection{GLEAM}

GLEAM (www.gleam.eu) is a simple land surface model fully dedicated to deriving evaporation based on satellite forcing only (Miralles et al., 2011b). It distinguishes between direct soil evaporation, transpiration from short and tall vegetation, snow sublimation, open-water evaporation, and interception loss from tall vegetation. Interception loss is independently calculated based on the Gash (1979) analytical model forced by observations of precipitation (Miralles et al., 2010). The remaining components of evaporation are based upon the formulation by Priestley and Taylor (1972), which does not require the parameterization of stomatal and aerodynamic resistances, in contrast to the Penman-Monteith equation. In the case of transpiration and soil evaporation, the potential evaporation estimates - resulting from the application of the Priestley and Taylor approach - are constrained by a multiplicative stress factor. This dynamic stress factor is calculated based on the content of water in vegetation (microwave vegetation optical depth; Liu et al., 2011) and the root zone (multilayer soil model driven by observations of precipitation and updated through assimilation of microwave surface soil moisture; see Martens et al., 2016). The consideration of vegetation water content accounts for the effects of plant phenology, while the root-zone soil moisture 
accounts for soil water stress. For regions covered by ice and snow, sublimation is calculated using a Priestley and Taylor equation with specific parameters for ice and supercooled waters (Murphy and Koop, 2005). For the fraction of open water at each pixel, the model assumes potential evaporation. GLEAM has recently been applied to look at trends in the water cycle (Miralles et al., 2014b) and land-atmospheric feedbacks (Guillod et al., 2015; Miralles et al., 2014a).

\subsubsection{PT-JPL}

The PT-JPL model by Fisher et al. (2008) uses the Priestley and Taylor (1972) approach to estimate potential evaporation. Unlike GLEAM, it applies a series of ecophysiological stress factors based on atmospheric moisture (vapour pressure deficit and relative humidity) and vegetation indices (normalized difference vegetation index, i.e. NDVI, and soil adjusted vegetation index) to constrain the atmospheric demand for water. This implies that the set of forcing requirements of PT-JPL is in fact very comparable to that of PMMOD (see Table 1). In order to partition land evaporation into soil evaporation, transpiration, and interception loss, PT-JPL first distributes the net radiation to the soil and vegetation components and then calculates the potential evaporation for soil, transpiration, and interception separately. The partitioning between transpiration and interception loss is done using a threshold based on relative humidity. As in PM-MOD, snow sublimation and open-water evaporation are not considered independently of other processes. The model has been employed in a number of studies to estimate terrestrial evaporation on regional and global scales in recent years (see, e.g., Sahoo et al., 2011; Vinukollu et al., 2011a, b).

\subsection{Input data}

One of the objectives of the WACMOS-ET project has been to correct for a recurring issue in inter-product evaluations of global evaporation: due to inconsistencies in the forcing data behind current evaporation products, it is difficult to attribute the observed inter-product disagreements to algorithm discrepancies (Jiménez et al., 2011; Mueller et al., 2013). Consequently, one of the first steps in WACMOS-ET has been to compile a reference input data set that has been used to run all models in a consistent manner. This consistency applies to both local-scale runs (in Part 1) and regional and global runs (in the present study). On the other hand, since neither the required input variables nor the models' sensitivity to these input variables and their uncertainties are the same for all models (see Table 1), it is not possible to fully attribute observed differences in performance to internal model errors. Nonetheless, our efforts to homogenize forcing data in a global evaporation inter-model comparison are unique, with the exception of Vinukollu et al. (2011a), who used offthe-shelf forcing data sets to run earlier versions of SEBS, PT-JPL, and PM-MOD. For all the details on the produc- tion of the reference input data set, the reader is directed to the thorough descriptions in Part 1 and the supporting documents available on the project website. Nonetheless, a short summary is also provided here.

Some of the variables considered in the reference input data set have been internally generated during the project, while others were selected from the existing pool of global climatic and environmental data sets. Choices regarding the spatial and temporal resolution, period covered, and study domain were made with the support of a large number of end users surveyed via the internet (see project website). The target grid resolution of WACMOS-ET is $25 \mathrm{~km}$, the domain is global and the study period spans 2005-2007. A 3-hourly temporal resolution maximizes the links with the work undertaken by the GEWEX LandFlux initiative to produce sub-daily evaporation estimates (McCabe et al., 2016). The present Part 2 evaluates the outputs after aggregating them to daily, monthly, and annual scales, while the skill of the models to resolve the diurnal cycle of evaporation is explored in Part 1. Although the internally generated input data sets were originally derived at a relatively fine $(<5 \mathrm{~km})$ spatial resolution, critical inputs not generated within the project were only available at $75-100 \mathrm{~km}$ (see below). Consequently, all input data sets have been spatially resampled to match the $25 \mathrm{~km}$ target resolution and reprojected onto a common sinusoidal grid before using them to run the evaporation models.

Internally developed products include the fraction of photosynthetically active radiation and leaf area index, which are derived to a large extent from European satellites (see Part 1). Data access, product descriptions, and user guidelines for these data sets are available to interested parties upon request via the project website. Whereas PM-MOD and PT-JPL apply these internally generated data sets to characterize vegetation phenology, GLEAM uses observations of microwave vegetation optical depth as a proxy for vegetation water content; these are taken from the data set of Liu et al. (2011) based on the Advanced Microwave Scanning Radiometer Earth Observing System (AMSR)-E at $0.25^{\circ}$ spatial resolution.

The remaining products comprising the reference input data set have been selected from the pool of available community data sets. Surface net radiation is obtained by integrating the upwelling and downwelling radiative fluxes from the NASA and GEWEX Surface Radiation Budget (SRB, Release 3.1), which contains global 3-hourly averages of these fluxes on a $1^{\circ}$ resolution grid. The SRB product is based on a range of satellite data, atmospheric reanalysis, and data assimilation (Stackhouse et al., 2004). The meteorology (i.e. near-surface air temperature, air humidity, and wind speed) comes from the ERA-Interim atmospheric reanalysis, provided at 3-hourly resolution (using the forecast fields) and at a spatial resolution of $\sim 75 \mathrm{~km}$. The reason for using atmospheric reanalysis data (based on observations assimilated into a weather forecast model), as opposed to direct satellite observations, is that some of these variables (like air 
temperature and humidity) are presently difficult to observe over continents, if not impossible (as in the case of wind speed), and are not routinely available at sub-daily time steps and for all weather conditions.

Despite its relevance for plant-available water and interception loss, precipitation is not a direct input for most global satellite-based evaporation models. The same applies to surface soil moisture, which can also be observed from space. From the WACMOS-ET models, only GLEAM uses observations of precipitation and surface soil moisture as input. In the reference input data set, precipitation data come from the Climate Forecast System Reanalysis for Land (CFSRLand; Coccia et al., 2015), which uses the Climate Prediction Center (CPC, Chen et al., 2008) and the Global Precipitation Climatology Project (GPCP, Huffman et al., 2001) daily data sets and applies a temporal downscaling based on the CFSR (Saha et al., 2010). For soil moisture, we use the satellite product of combined active-passive microwave surface soil moisture by Liu et al. (2012), which combines information from scatterometers and radiometers from different platforms, and was developed as part of the ESA Climate Change Initiative (CCI). In addition, GLEAM also uses information on snow water equivalents that is taken from the ESA GlobSnow product, version 1.0 (Luojus and Pulliainen, 2010), based on AMSR-E and corrected using ground-based measurements. Since GlobSnow covers the Northern Hemisphere only, data from the National Snow and Ice Data Center (NSIDC) are used in snow-covered regions of the Southern Hemisphere (Kelly et al., 2003). Observations of soil moisture and snow water equivalents have a native resolution of $0.25^{\circ}$ and are imported into GLEAM at daily time steps.

\subsection{Data used for evaluation}

\subsubsection{Other global land evaporation products}

For the purpose of comparing our three WACMOS-ET products to related evaporation data sets, we incorporate two additional data sets into the evaluation: the ERA-Interim reanalysis evaporation (Dee et al., 2011) and the MTE product (Jung et al., 2009, 2010). The latter is derived from satellite data and FLUXNET observations (Baldocchi et al., 2001) using a machine-learning algorithm. In the model, tree ensembles are trained to predict monthly eddy-covariance fluxes based on meteorological, climate, and land cover data. It has a monthly temporal resolution and $0.5^{\circ}$ spatial resolution. For full details, the reader is referred to Jung et al. (2009).

\subsubsection{Catchment water balance data}

The mass balance of a catchment implies that the space and time integration of precipitation $(P)$ minus river run-off $(Q)$ should equal evaporation (integrated over the same space and time). This requires the consideration of a long period, so changes in storage within the catchment and the travel time of precipitation through the landscape can be neglected (see discussion in Sect. 3.3). Given that river run-off and precipitation are more easily and extensively measured than evaporation, estimates of $P-Q$ based on ground measurements of these two fluxes provide a convenient means to evaluate evaporation over large domains and long periods (Liu et al., 2014; Miralles et al., 2011a; Vinukollu et al., 2011b; Sahoo et al., 2011). Here, we use globally distributed multiannual river discharge data for basins larger than $2500 \mathrm{~km}^{2}$. Discharge data and watershed boundaries are obtained from the Global Runoff Data Centre (GRDC). Run-off data have been converted from cubic metres per second to millimetres per year using the area of each catchment as reported by the GRDC; basins where the absolute difference between the GRDC-reported area and the area calculated from basin boundaries exceeded $25 \%$ have been excluded from the analyses.

Precipitation for the target period 2005-2007 is taken from GPCP (Huffman et al., 2001) and the Global Precipitation Climatology Centre (GPCC) v6 (Schneider et al., 2013). Two versions of GPCC v6 are processed by applying relative gauge correction factors according to Fuchs et al. (2001) and Legates and Willmott (1990) to the native GPCC products as recommended by the producers. We further discard basins with (a priori) low-quality precipitation due to the low density of rain gauges $\left(<0.1\right.$ per $0.5^{\circ}$ latitude-longitude), frequent snowfall ( $>25$ days per year based on CloudSat), or where cumulative values of discharge exceed those of precipitation over the 3-year period. Finally, radiation data from the NASA Clouds and Earth's Radiant Energy System (CERES) Synoptic Radiative Fluxes and Clouds 1-degree resolution (SYN1deg) product (Wielicki et al., 2000) are used to exclude basins where $P-Q$ exceeds surface net radiation on average.

This results in a record of 837 basins from which $P$ $Q$ values are calculated. Figure 1 illustrates the locations of the centroids of these catchments. Basins are then clustered in 30 classes based on log-transformed precipitation, net radiation, and evaporative fraction (i.e. evaporation over net radiation). This is done in order to reduce noise and retain clear patterns for evaluation. The clustering algorithm used is a $k$ means with city block distance, with variables transformed to zero mean and unit variance. For clarity, each of the 30 classes is assigned to one of four groups based on thresholds of net radiation $\left(80 \mathrm{~W} \mathrm{~m}^{-2}\right)$ and evaporative fraction (0.5) as shown in Fig. 1. The results of comparing the evaporation products, integrated over the corresponding basins, to the $P-Q$ estimates are presented in Sect. 3.3. 


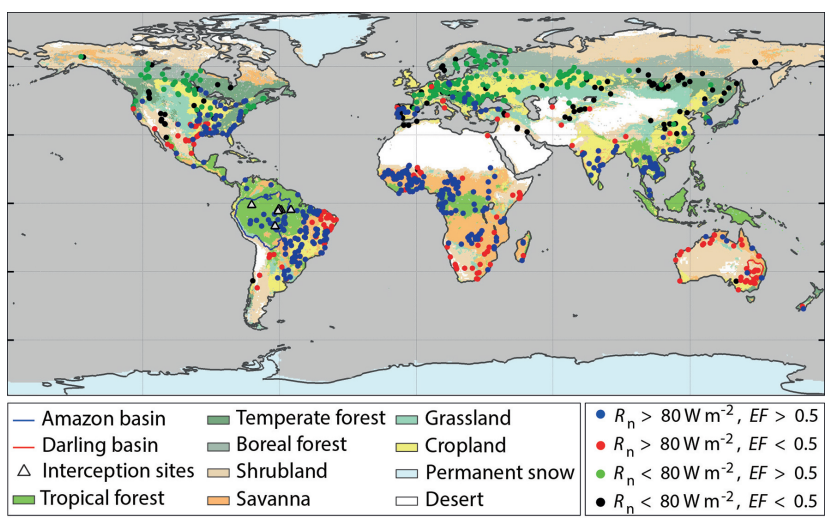

Figure 1. Climatic regimes and biomes considered in the evaluations. The background map illustrates the land use classification scheme of the International Geosphere-Biosphere Programme (IGBP) used in Fig. 8. The Darling Basin in southeastern Australia, as considered in Sect. 3.2, is contoured in red. The Amazon Basin, as considered in Sect. 3.4, is marked in blue, with white triangles indicating the locations of past interception loss campaigns. Dots indicate the centroids of the 837 basins used in the analyses presented in Sect. 3.3.

\section{Results and discussion}

\subsection{Global magnitude of terrestrial evaporation}

The global mean annual volume of evaporation has been intensively debated in recent years (see, e.g., Wang and Dickinson, 2012), with the range of reported global averages in current Coupled Model Intercomparison Project Phase 5 (CMIP5) models being large (Wild et al., 2014) and observational benchmark data sets also differing significantly (Mueller et al., 2013). In this section, we aim to give some context to the global magnitude of evaporation that results from the WACMOS-ET analyses by contrasting the results with alternative evaporation data sets and existing literature. Unless otherwise noted, results come from aggregating the outputs of the 3-hourly global runs based on the $25 \mathrm{~km}$ spatial resolution of the reference input data set for the period 2005-2007.

Overall, the total annual magnitude of evaporation estimated by the WACMOS-ET models amounts to $54.9 \times 10^{3} \mathrm{~km}^{3}$ for PM-MOD, $72.9 \times 10^{3} \mathrm{~km}^{3}$ for GLEAM, and $72.5 \times 10^{3} \mathrm{~km}^{3}$ for PT-JPL. We further calculated $84.4 \times 10^{3} \mathrm{~km}^{3}$ for ERA-Interim and $68.3 \times 10^{3} \mathrm{~km}^{3}$ for MTE based on the same 2005-2007 period. Unlike the other products, MTE does not include poles and desert regions (as shown in Fig. 2); however, the contribution from these areas to the global volumes is rather marginal $(<5 \%$ based on our analyses). For comparison, values typically found in the literature based on a broad variety of methodologies and forcings are $63.2 \times 10^{3} \mathrm{~km}^{3}$ (Zhang et al., 2016), $65.0 \times 10^{3} \mathrm{~km}^{3}$ (Jung et al., 2010), $65.5 \times 10^{3} \mathrm{~km}^{3}$ (Oki and Kanae, 2006), $65.8 \times 10^{3} \mathrm{~km}^{3}$ (Schlosser and Gao, 2010), $67.9 \times 10^{3} \mathrm{~km}^{3}$

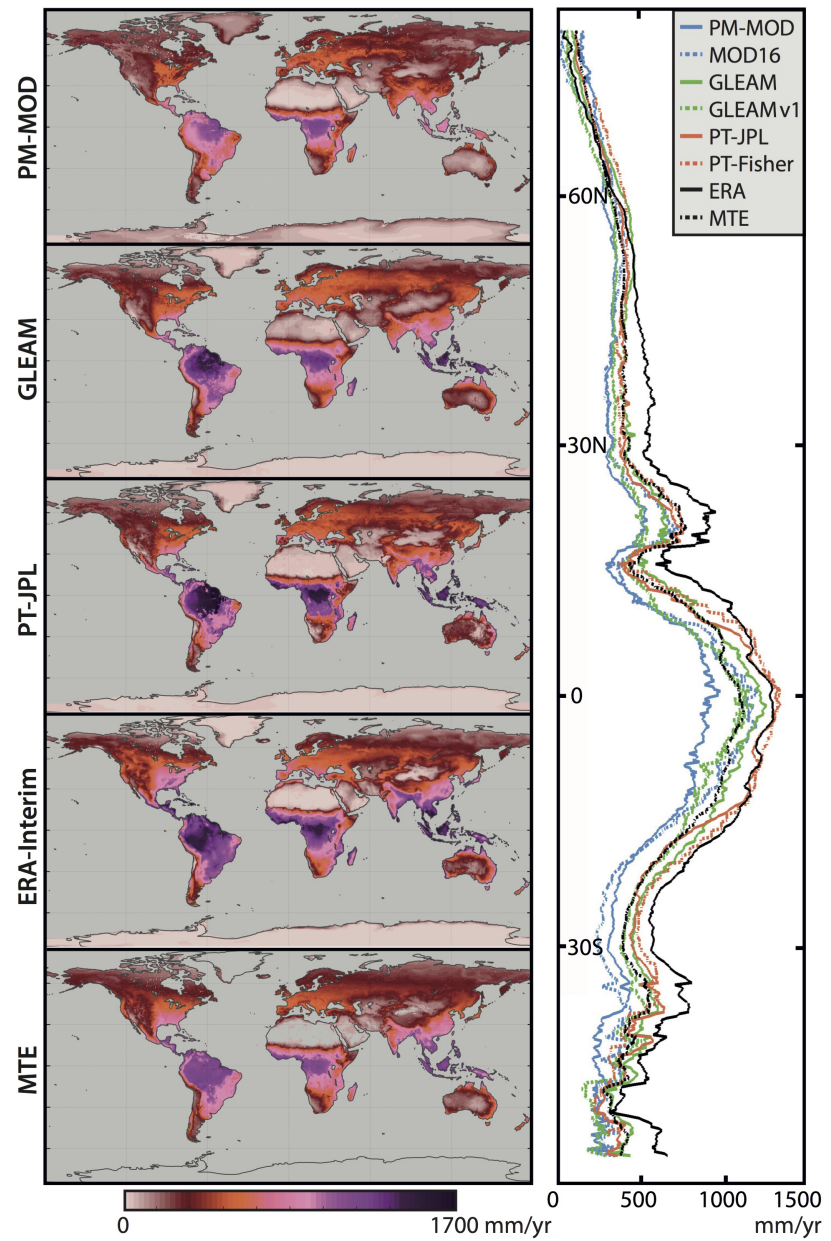

Figure 2. Mean patterns of land evaporation. Average evaporation during 2005-2007 for PM-MOD, GLEAM, and PT-JPL forced by the reference input data set; the ERA-Interim reanalysis and the MTE product are shown for comparison. On the right, the latitudinal profiles of evaporation; the original data sets of PM-MOD, GLEAM, and PT-JPL (i.e. MOD16, GLEAMv1, and PT-Fisher, respectively) are also shown for comparison. We note that the original PT-JPL covers until 2006 only, and therefore its latitudinal profile is based on the 2005-2006 average. Due to the MTE product not reporting values in polar regions and deserts, those areas are excluded from the latitudinal profiles in all models.

(Miralles et al., 2011a), $71 \times 10^{3} \mathrm{~km}^{3}$ (Baumgartner and Reichel, 1975), $73.9 \times 10^{3} \mathrm{~km}^{3}$ (Wang-Erlandsson et al., 2014), and $74.3 \times 10^{3} \mathrm{~km}^{3}$ (Zhang et al., 2015). We note again that some of these studies considered the poles and desert regions, while others did not. Further, the study period considered in WACMOS-ET is 2005-2007, while previously reported annual averages may be based on different periods.

In Fig. 2 the multiannual (2005-2007) mean evaporation is displayed for the different products, including also MTE and ERA-Interim for comparison. All five data sets capture the expected climatic transitions well, although disagreements on the regional scale are still considerable (see below). Lat- 
itudinal averages are illustrated in the right panel of Fig. 2. Model estimates are normally contained between the low values from PM-MOD and the high values from ERA-Interim; as an exception, PM-MOD can be comparatively large in Northern Hemisphere high latitudes (see Sect. 3.2). In Fig. 2, the latitudinal profiles from the original and official products of PM-MOD (i.e. MOD16), GLEAM (i.e. GLEAM v1), and PT-JPL (i.e. PT-Fisher) are also displayed for comparison. Note that the main differences between these official products and those developed in WACMOS-ET relate to the choice of forcing - see Mu et al. (2013), Miralles et al. (2011a), and Fisher et al. (2008) for the particular forcing data used to generate these official data sets. In addition, models have been run here on a sub-daily scale ( 3 hourly) as opposed to their original daily (PM-MOD, GLEAM) or monthly (PT-JPL) temporal resolutions. While for PM-MOD and PT-JPL the choice of temporal resolution and forcing in WACMOS-ET leads to overall lower values (see PM-MOD in tropics), values are slightly higher than in the original version (v1) for GLEAM.

Inter-product differences in mean evaporation become more evident in Fig. 3, which presents the anomalies for each product calculated by subtracting the average of the fiveproduct ensemble. PM-MOD displays lower averages than the multi-product ensemble mean over the entire continental domain, with the exception of high latitudes, as discussed above. GLEAM shows higher than average values in Europe or Amazonia and lower than average values in North America. This pattern is somewhat shared by PT-JPL, although the two models disagree substantially in water-limited regions of Africa and Australia, even if absolute mean values are low in these regions (see Fig. 2). This relates to the different model representation of evaporative stress, with GLEAM being based on observations of rainfall, surface soil moisture, and vegetation optical depth, while PT-JPL is based on air humidity, maximum air temperature, and NDVI. As mentioned in Sect. 2.2, it is important to note that even though we aimed to maximize consistency in forcing data for PMMOD, GLEAM, and PT-JPL, their disagreement still reflects a combination of algorithm structural errors and input uncertainties, given the use of a distinct range of inputs for each model (Table 1) and the different model sensitivities to each particular driver.

ERA-Interim values are often at the high end of the predictions, consistent with the results by Mueller et al. (2013), more than doubling the evaporation estimated by PM-MOD on some occasions (Fig. 2). MTE values, on the other hand, are lower than the inter-product average in the Himalayas and in tropical forests - which may potentially relate to the lack of a separate computation of interception loss and the open question of whether interception can be measured with eddy-covariance instruments (see van Dijk et al., 2015) - but they agree well with the mean of the multi-product ensemble in other regions (Fig. 3). A quick overview of the range of uncertainty that can be expected may be found in the right

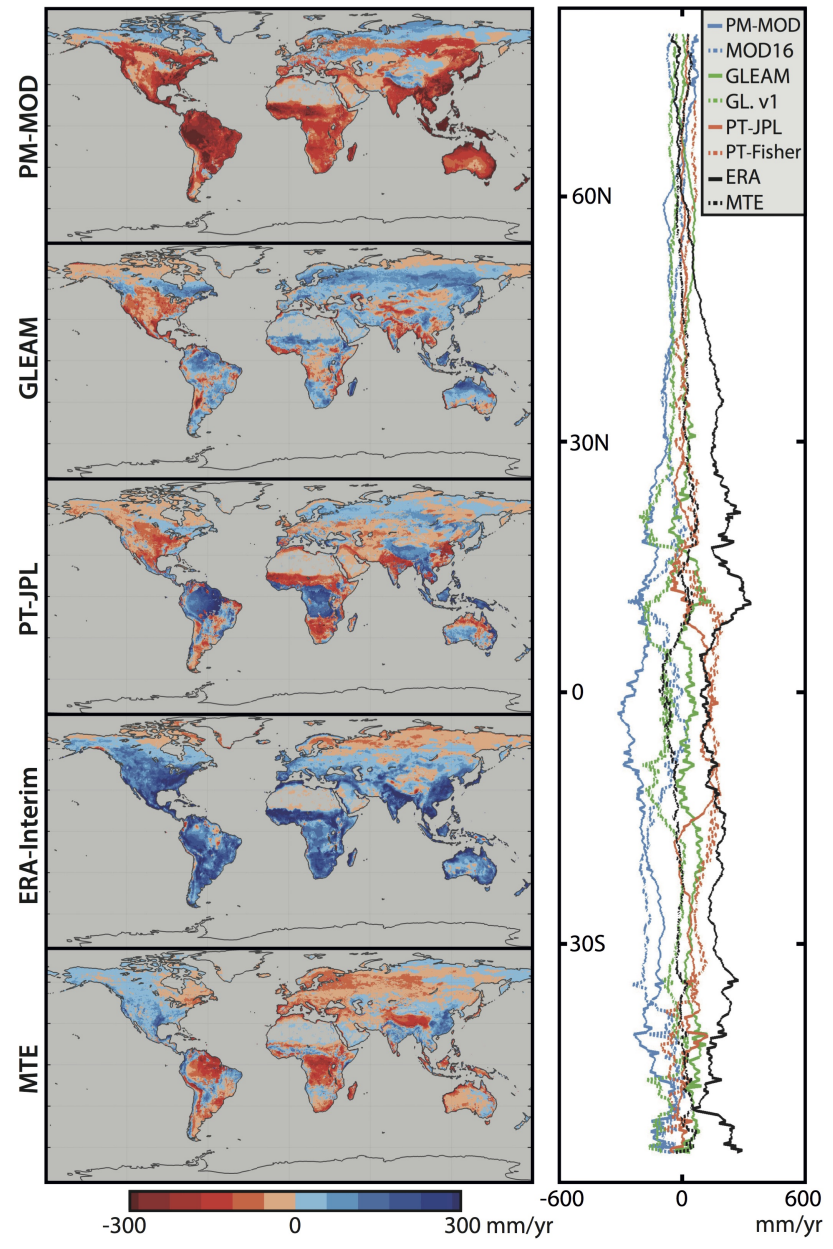

Figure 3. Long-term anomalies of evaporation, as in Fig. 2 but based on the anomalies for each product calculated as the mean of each particular product (i.e. the maps in Fig. 2) minus the interproduct ensemble mean (considering the ensemble of five models). Grey areas over the continents correspond to regions where MTE displays no estimates of evaporation.

panel of Fig. 3, where the latitudinal profiles of anomalies are illustrated. Data sets appear again to be confined between the low values of PM-MOD and the high values of ERAInterim. If this multi-model range is interpreted as an indication of the uncertainty, it is worth noting that it often amounts to $60-80 \%$ of the mean evaporation, particularly in the subtropics. In the tropics, while the relative uncertainty is lower, the inter-product range still reaches $\sim 500 \mathrm{~mm} \mathrm{yr}^{-1}$ according to the latitudinal profiles in Fig. 3. To put that volume into context, the mean annual evaporation is below $500 \mathrm{~mm} \mathrm{yr}^{-1}$ for more than $50 \%$ of continental surfaces, according to the inter-product ensemble mean.

The spatial agreement among models is further explored in Fig. 4, which presents the spatial correlation for each pair of models based on their long-term global means (i.e. the maps in Fig. 2). Each land pixel is an independent point in the scat- 

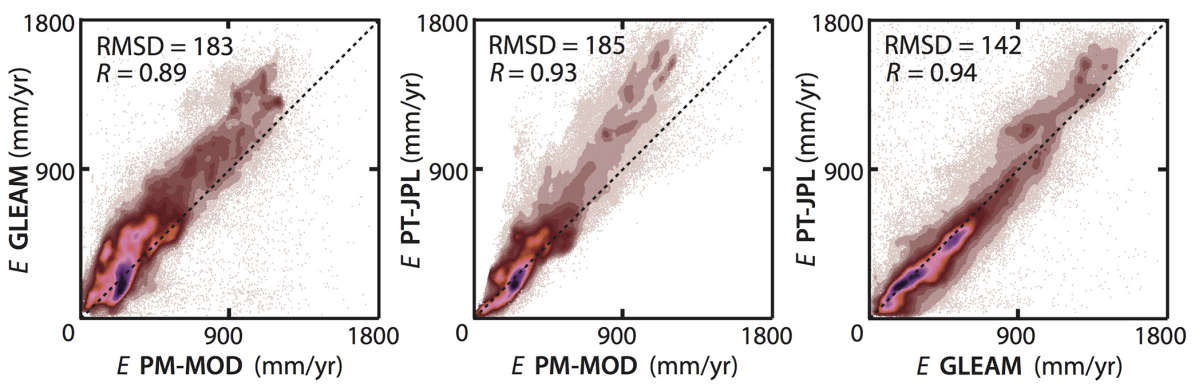

Figure 4. Correspondence in the average spatial patterns for each pair of models. Each point represents a land pixel in Fig. 2. Pearson's correlation coefficients $(R)$ and root mean square differences (RMSDs) are listed.

ter. The lowest spatial correlation occurs between PM-MOD and GLEAM $(R=0.89)$ and the highest between GLEAM and PT-JPL $(R=0.94)$. Although the latter fact may reflect the common choice of a Priestley and Taylor approach to calculate potential evaporation in both models, it occurs despite their large differences in input requirements (Table 1) and in the approach to deriving evaporative stress and interception loss (Sect. 2.1). The agreement in the mean spatial patterns between PM-MOD and PT-JPL is also high in terms of the correlation coefficient $(R=0.93)$, as expected from their shared set of input variables (see Table 1). Nonetheless, their root mean square difference is large $\left(\mathrm{RMSD}=185 \mathrm{~mm} \mathrm{yr}^{-1}\right.$ ) compared to the difference between PT-JPL and GLEAM $\left(\mathrm{RMSD}=142 \mathrm{~mm} \mathrm{yr}^{-1}\right.$ ), which mostly reflects the overall lower values of PM-MOD. These low mean values are also accompanied by a low variance, especially in midlatitudes. This is illustrated in Fig. 5, which depicts the standard deviation of the monthly time series at each pixel and as a function of latitude.

\subsection{Temporal variability of terrestrial evaporation}

In addition to long-term mean differences in evaporation, inter-product discrepancies in temporal dynamics are certainly expected. Temporal correlations based on the (20052007) daily time series for each pair of models are illustrated in Fig. 6a. The overall agreement in temporal dynamics is larger in high latitudes, especially between GLEAM and PT-JPL. In semi-arid regions, product-to-product correlations are often below 0.5 and may drop below 0.2 (see, e.g., low correlation between PM-MOD and PT-JPL in southern Africa or Australia). This occurs despite the substantial amplitude of the seasonal cycle in these transitional regimes (see, e.g., Fig. 5), which may, in principle, artificially increase temporal correlations. Overall, Fig. 6a corroborates that, although the agreement between GLEAM and PT-JPL is large, their different approach to estimating wateravailability constraints on evaporation and rainfall interception loss leads to significant differences for semi-arid regions and tropical forests.

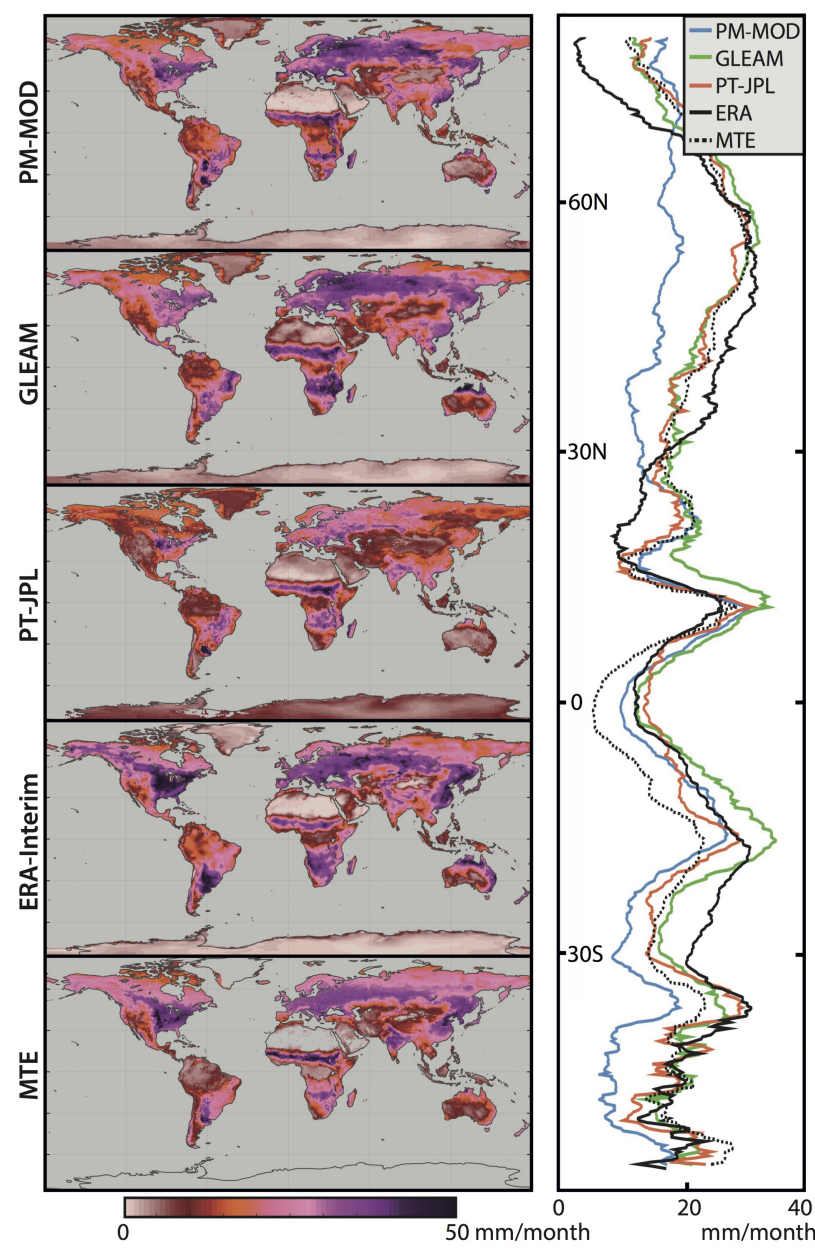

Figure 5. Standard deviation of land evaporation, based on the monthly time series for 2005-2007 at each pixel for PM-MOD, GLEAM, and PT-JPL forced by the reference input data set; the ERA-Interim reanalysis and the MTE product are shown for comparison. The right column illustrates the latitudinal profiles of these standard deviations. Due to the MTE product not reporting values in polar regions and deserts, these areas are excluded from the latitudinal profiles in all models. 


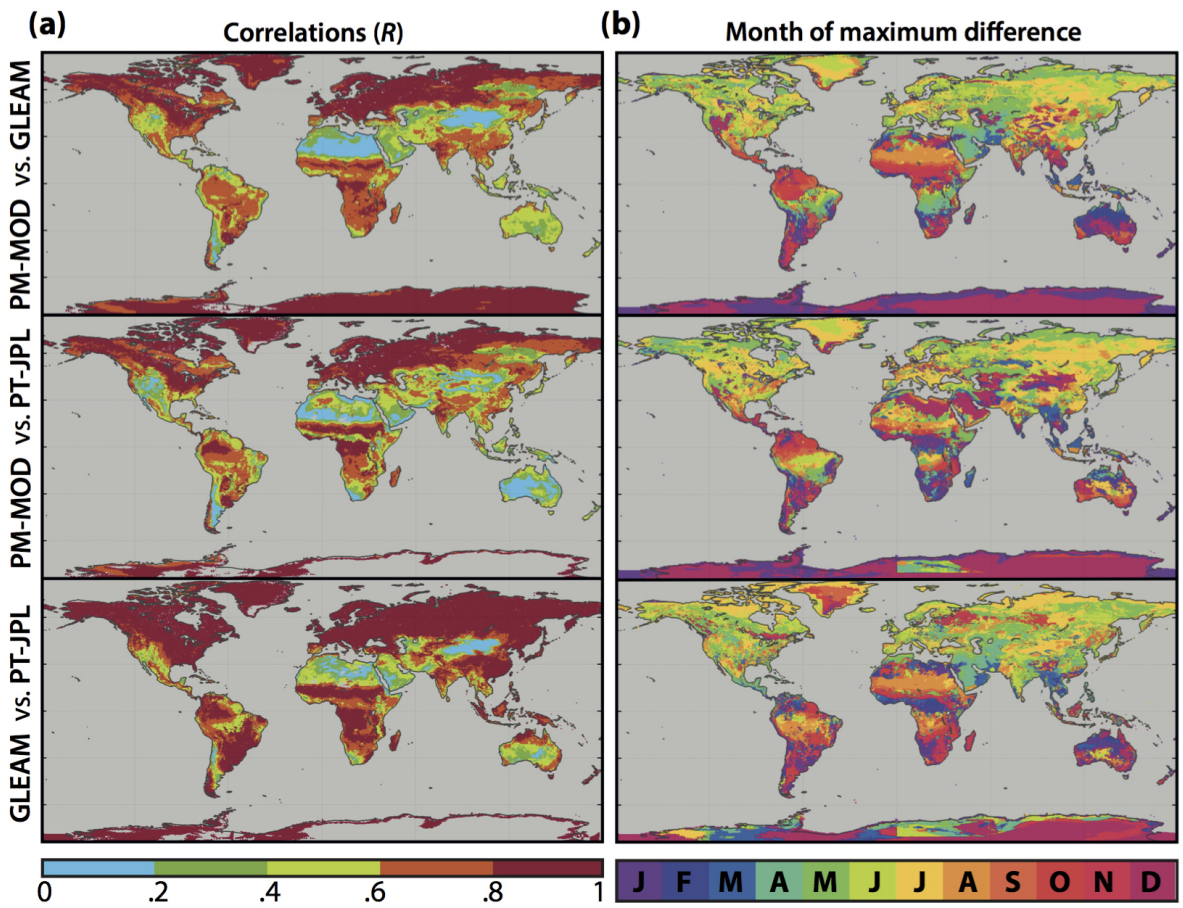

Figure 6. Temporal agreement between the models. Panel (a): temporal correlation coefficients between each pair of products based on the daily (2005-2007) time series. Panel (b): month of the year in which the maximum (monthly) difference occurs between a particular pair of products based on their monthly climatologies.

Based on the monthly climatology of each model (calculated by averaging the estimates for the same month of the year and considering the multiannual 2005-2007 period), Fig. $6 \mathrm{~b}$ illustrates the month in which the differences between a given pair of models are the largest. In the Northern Hemisphere, the product-to-product differences are at their maximum during summertime, when the flux of evaporation is high. This is particularly the case in comparisons to PM-MOD, given that the seasonal evaporation peak of PMMOD is often less pronounced than for the other models (see also Figs. 5, 7, and 8). In the tropics and the Southern Hemisphere, maximum differences between models occur at different times of the year but often coincide with months of higher evaporative demand for water; this is the case for southern Africa, the pampas region or Australia during the Austral summer.

Figure 7 shows the average evaporation for boreal summer (JJA) and winter (DJF) for each model based on the 3year period of study. MTE and ERA-Interim are again included for comparison. As expected, the seasonal variability of evaporation follows the annual cycle of radiation, except for arid and semi-arid regions that are controlled by the availability of water. The lower values of PM-MOD are again highlighted. The underestimation of PM-MOD, with respect to the other two models, mostly occurs at times and in locations for which both evaporative demand and water availability are high (e.g. midlatitude summer, tropics); thus, evapora- tion is expected to be high as well. As discussed in Sect. 3.3, this may be associated with an overestimation of evaporative stress in the model. However, PM-MOD is often higher than the other two models in periods and regions where radiation is severely limited, potentially due to the underestimation in Priestley-Taylor-type models (i.e. GLEAM and PT-JPL) when radiation is not the main supply of energy for evaporation (see, e.g., Parlange and Katul, 1992); in these conditions, the Penman-Monteith equation still considers adiabatic sources of energy to drive evaporation. Once more, differences in seasonal means between GLEAM and PT-JPL exist on regional scales, especially in water-limited regimes, with Australia being a clear example (see also Fig. 9).

Nonetheless, Fig. 7 still shows a general agreement amongst the five models in their representation of seasonal dynamics. This agreement also becomes apparent in Fig. 8, which presents the seasonal monthly climatology of evaporation over different biome types. Except for densely vegetated regions (see, e.g., Southern Hemisphere tropical forests), arctic regions, or arid regimes (see, e.g., Northern Hemisphere deserts), all models capture similar monthly dynamics. This occurs despite the systematic differences in the absolute magnitudes of evaporation, which again become apparent, especially between PM-MOD and ERA-Interim, and may indicate limitations in the way models represent the processes governing land evaporation. This highlights the importance 


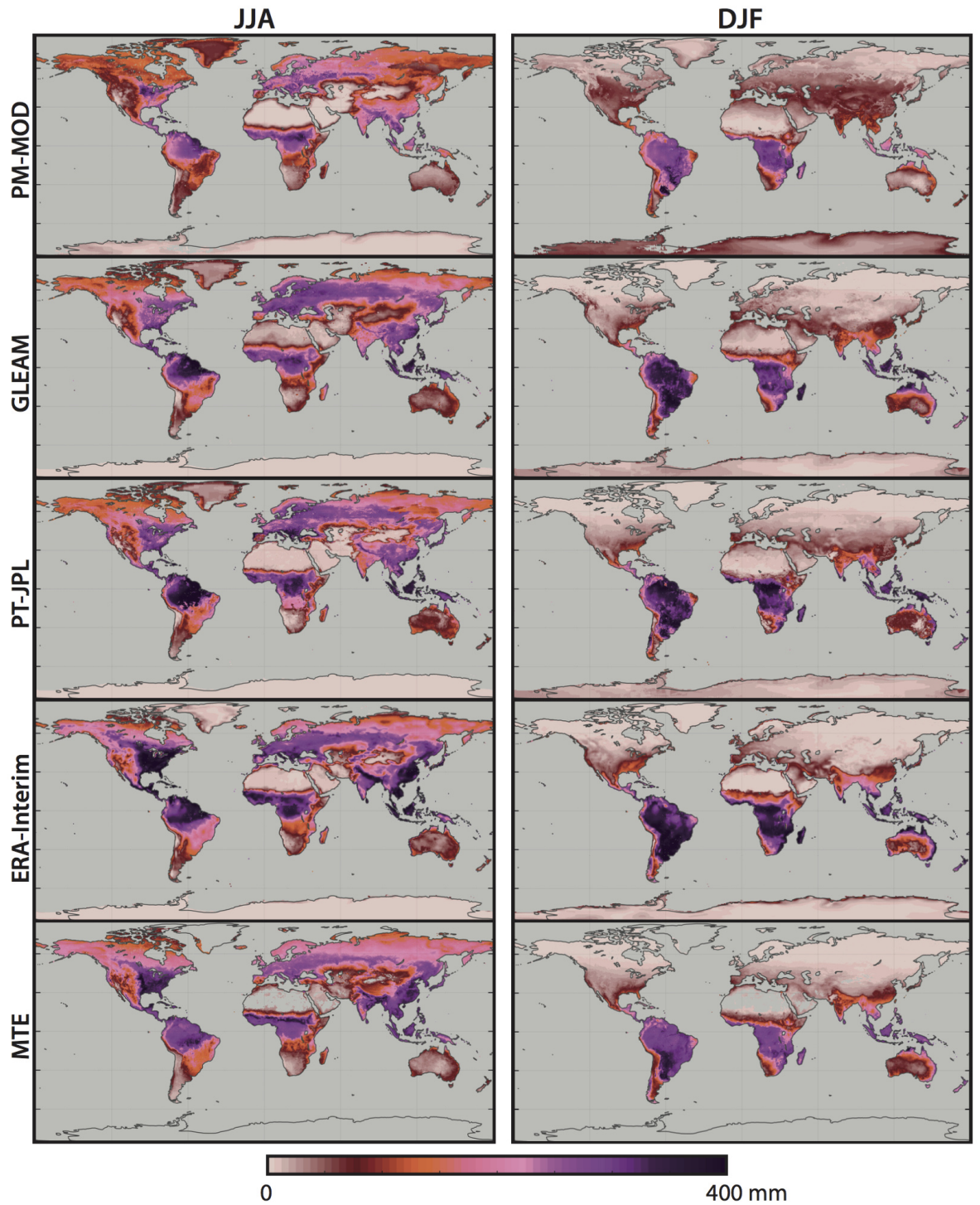

Figure 7. Mean seasonal differences. Average evaporation for PM-MOD, GLEAM, and PT-JPL during boreal summer (June, July, and August) and austral summer (December, January, and February). ERA-Interim reanalysis and MTE are considered for comparison. The 3 years of data (2005-2007) are used in the calculation of these seasonal averages.

of field-based validation activities to improve and select algorithms.

Since the seasonality of evaporation is mostly dominated by the annual cycle of irradiance in nature (especially in energy-limited regions), the skill of these models in correctly capturing these seasonal dynamics relies mostly on adequately representing the sensitivity of evaporation to the (common) net radiation forcing. However, if estimating average seasonal dynamics in evaporation may not appear overly challenging from the modelling perspective, accurately simulating anomalies (i.e. departures) relative to a seasonal expectation is far more problematic. With hydro-meteorological extremes - and particularly droughts - being a target application of these models, correctly reproducing the effect of sur- face water deficits on evaporation (and vice versa) appears crucial. One of the most remarkable hydro-meteorological extremes that coincide with the WACMOS-ET period is the Australian Millennium Drought, which affected (especially) southeastern Australia and had one of its most severe years of rainfall deficits in 2006 (see van Dijk et al., 2013; Leblanc et al., 2012). Figure 9 (top panel) shows the daily time series of latent heat flux and net radiation for the Darling Basin (area contoured in Fig. 1) from the three WACMOS-ET models during 2005-2007; ERA-Interim is also included for comparison. Figure 9 (bottom panel) presents the monthly aggregates of land evaporation from these models and incorporates the estimates from MTE, precipitation from GPCC v6 (with 


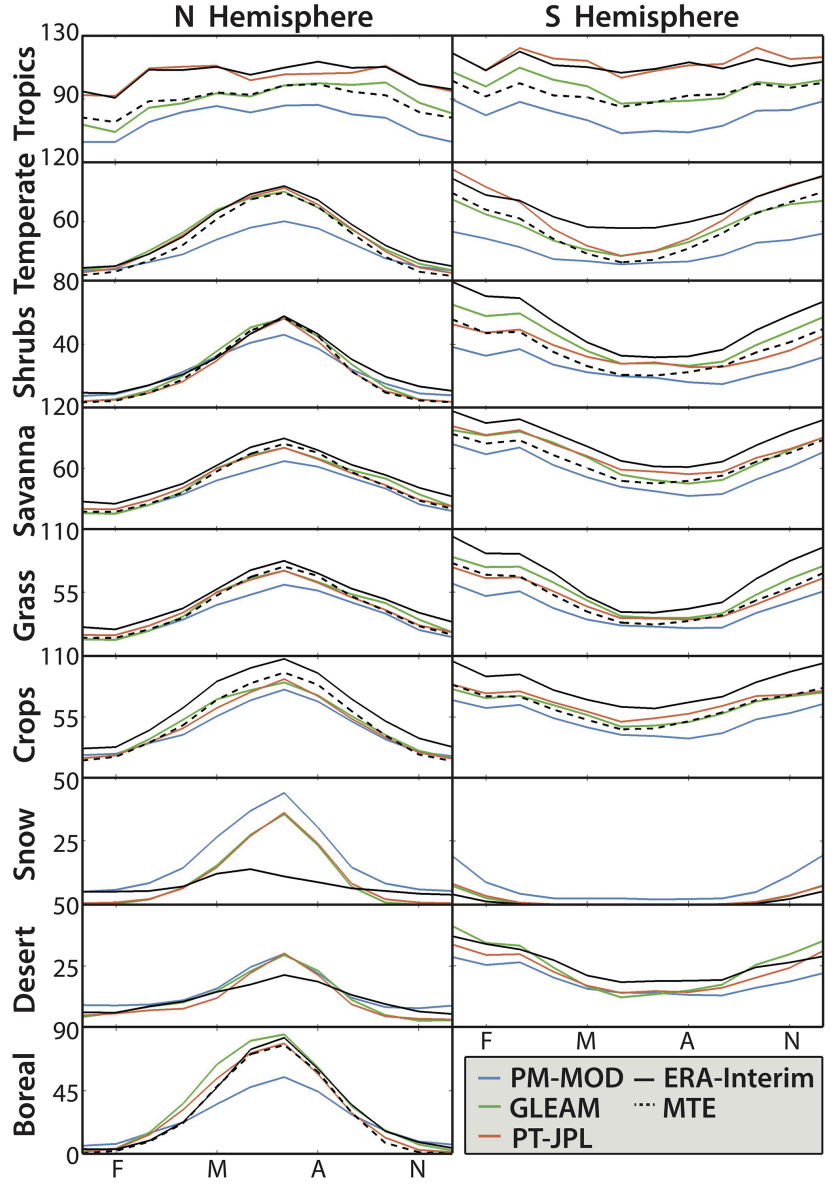

Figure 8. Average seasonal cycle. Monthly climatology of evaporation for each IGBP biome (see Fig. 1 for the global distribution of biomes) based on the 2005-2007 period. Northern Hemisphere (left panels) and Southern Hemisphere (right panels) are presented separately. In addition to the PM-MOD, GLEAM, and PT-JPL results, the evaporation from ERA-Interim and MTE is also shown for completeness. Fluxes are displayed in millimetres per month.

gauge correction factors from Fuchs et al., 2001), and river discharge data from GRDC.

Given the dominant rainfall scarcity, monthly run-off volumes are very low (note the difference of more than 2 orders of magnitude between the left and right axes in the bottom panel of Fig. 9); the river in fact dries out completely for prolonged periods. This indicates that almost the entire volume of incoming rainfall is evaporated. Therefore, cumulative evaporation should approximate cumulative precipitation over the multi-year period. We find, however, that in the case of all models, evaporation exceeds total rainfall, except for PM-MOD, in which evaporation is only $66 \%$ of precipitation. In the case of MTE, the cumulative evaporation is $16 \%$ higher than the precipitation, while it is 21 and $29 \%$ higher for GLEAM and PT-JPL, respectively, and as much as $56 \%$ higher for ERA-Interim. To some extent, this could reflect the progressive soil dry-out as the drought event evolves

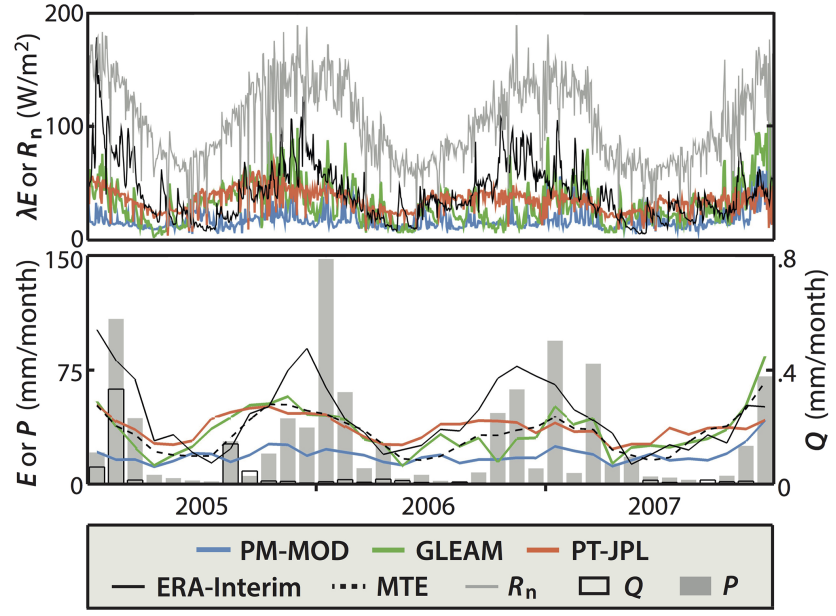

Figure 9. Evaporation during the Australian Millennium Drought. Top panel: daily time series of surface net radiation (SRB 3.1) and latent heat flux from the three WACMOS-ET products for the Darling Basin during 2005-2007. ERA-Interim latent heat flux is also illustrated for comparison. Bottom panel: monthly time series of evaporation, precipitation (GPCC v6 with gauge correction factors from Fuchs et al., 2001), and discharge (GRDC). The contributing area is shown in Fig. 1.

(i.e. the negative change in soil storage in time), the use of irrigation, or the accessibility of groundwater for root uptake (see, e.g., Chen and Hu, 2004; Orellana et al., 2012). Nonetheless, there is a general tendency in all models to overestimate evaporation in drier catchments, as shown in the following section (Sect. 3.3). Once more, Fig. 9 shows that the estimates from the different products typically range between the low values of PM-MOD and high values of ERAInterim and that there is a general agreement on the temporal dynamics between GLEAM, PT-JPL, and MTE. Nevertheless, there are clear differences in the timing of water stress and the rates of evaporation decline (see, e.g., summer 2006), and the inter-product disagreement on short temporal scales (Fig. 9) is considerably larger than the disagreement in mean seasonal cycles (Fig. 8).

\subsection{Evaluation of evaporation based on the water balance closure}

The skill of the different models to close the water budgets over 837 basins is investigated here. As explained in Sect. 2.3.2, these analyses consist of a comparison of modelled evaporation estimates from PM-MOD, GLEAM, and PT-JPL (forced by the reference input data set over 20052007 ) with estimates of $P-Q$. Such a comparison implies the validity of a series of assumptions (see discussion below), but overall, $P-Q$ estimates remain a valid, recursive means to evaluate long-term evaporation patterns (Liu et al., 2014; Miralles et al., 2011a; Vinukollu et al., 2011b; Sahoo et al., 2011). Here, different criteria have been applied to ensure 
the quality of the $P-Q$ estimates, and the remaining catchments (Fig. 1) have been clustered into 30 different classes based on average precipitation and evaporative fraction (see Sect. 2.3.2).

The skill of the three WACMOS-ET models to reproduce the general climatic patterns of evaporation becomes apparent from the scatterplots in Fig. 10. All three WACMOSET products correlate well with the observations, which implies that their long-term spatial distribution of evaporation (Fig. 2) is, overall, realistic. The general negative bias of PMMOD becomes discernible again when compared to the $P-$ $Q$ data, a finding which is in agreement with the results by Mu et al. (2013). In addition, there is a tendency in all models to underestimate evaporation in wet regions and overestimate it in dry regions; the latter was already suggested by Fig. 9. While this pattern could potentially be explained by systematic errors in $P-Q$, the same tendency has been found in Part 1 in comparisons with independent eddy-covariance towers. Once more, it is interesting to see how the independent evaporation data sets, i.e. ERA-Interim and MTE, perform in this comparison; both products correlate well with the $P-Q$ estimates, although the overall higher values of ERA-Interim (and lower of MTE) are again highlighted, together with the tendency to overestimate evaporation in dry catchments and underestimate it in wet ones, which is shared by all five data sets.

As mentioned above, the use of $P-Q$ as a benchmark for evaporation depends on the validity of several assumptions. First, the catchment needs to be watertight (no subsurface leakage to other catchments) and its geographical boundaries must be well defined. Second, the entire volume of river water that is extracted for direct human use must return to the river, and it should do so upstream of the staff gauge location. Third, the lag time between rainfall events and the discharge measured at the station can be neglected when compared to the total period of study. Finally, the changes in soil water storage within the catchment should be insignificant compared to the cumulative volume of the three main hydrological fluxes. Here, by considering long-term averages of $P-Q$, these assumptions appear to be reasonable for most continental regions. However, for industrialized areas with a dense population, the consumption and export of water and the human regulation of the reservoir storages may compromise these assumptions. Nonetheless, the largest sources of uncertainty regarding the use of $P-Q$ as an estimate of catchment evaporation likely come from (a) the definition of the run-off-contributing area and (b) errors in precipitation and discharge observations. In fact, Fig. 10 shows that the choice of precipitation product can have a significant influence on the results, even despite the existing interdependencies between the gauge-based precipitation data sets tested here (Sect. 2.3.2). On the other hand, uncertainties in observations of river run-off can also be significant and come from errors in the measurements of water height, the discharge data used to calibrate the rating curves, or the interpolation

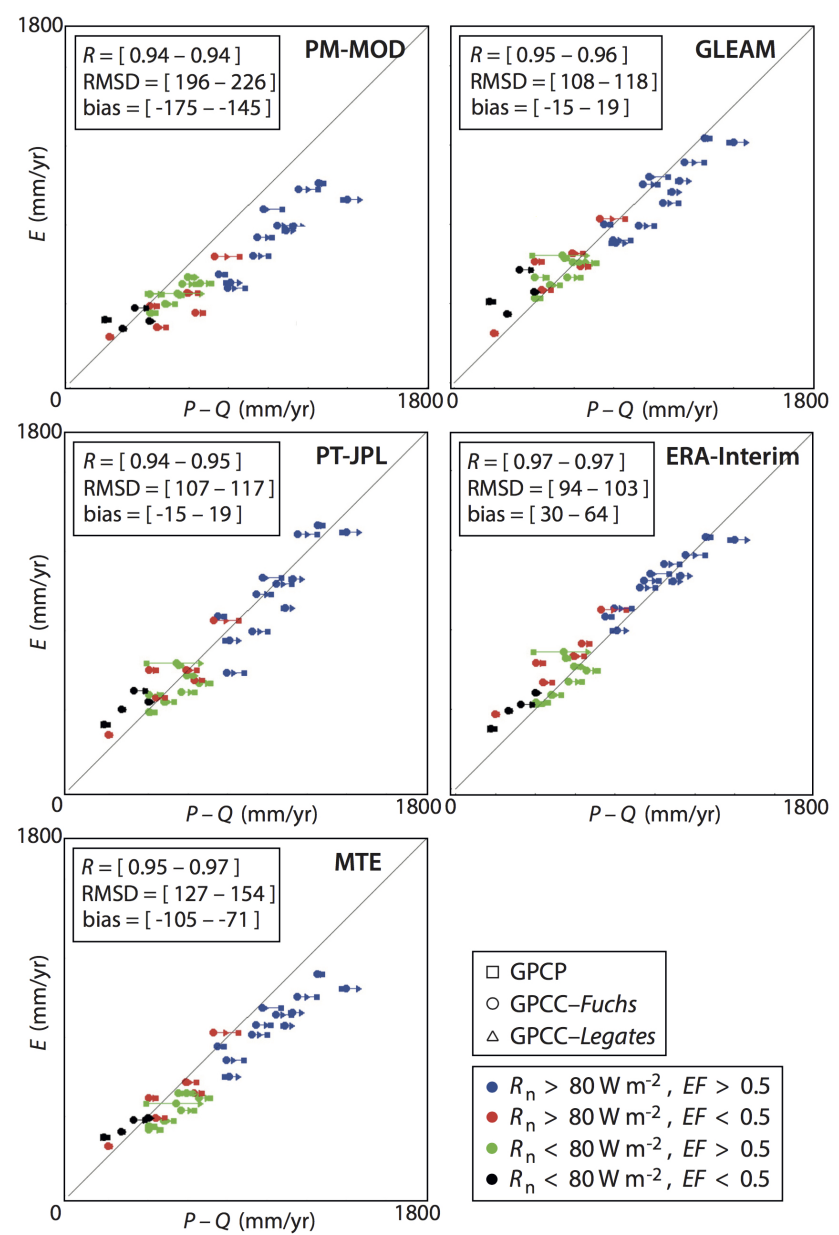

Figure 10. Skill to close catchment water budgets. Correlations between the long-term averages in evaporation from the three WACMOS-ET models and $P-Q$ estimates based on observations from 837 catchments. ERA-Interim and MTE are added for the sake of completeness. Three different precipitation products are considered in the calculation of $P-Q$ : GPCP, GPCC v6 with gauge correction factors from Fuchs et al. (2001), and GPCC v6 with gauge correction factors from Legates and Willmott (1990). The corresponding validation statistics are noted within the scatterplots, and the range displayed for each statistical inference derives from the use of the three different precipitation products.

and extrapolation due to changes in riverbed roughness, hysteresis effects, etc. (see, e.g., Di Baldassarre and Montanari, 2009). Finally, it is important to note that model estimates correspond to the period 2005-2007, while $P-Q$ estimates do not necessarily span the entire period due to limitations in the availability of discharge data.

Additionally, the fit of the models to a Budyko curve (Budyko, 1974) is explored in Fig. 11 as a general diagnostic for the robustness of mean evaporation estimates and their consistency with the input of water and energy. Potential evaporation estimates are taken from the corresponding models, and precipitation is taken from the GPCC v6 prod- 

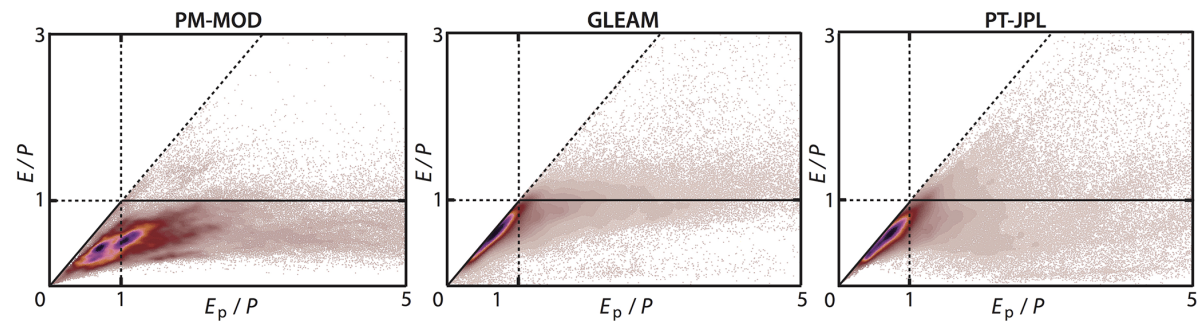

Figure 11. Budyko diagrams for the different models. Budyko curves derived for PM-MOD, GLEAM, and PT-JPL. Each point represents a different land grid cell. The horizontal axis presents the ratio of potential evaporation to precipitation $\left(E_{\mathrm{p}} / P\right)$ and the vertical axis presents the ratio of evaporation to precipitation $(E / P)$. Actual and potential evaporation estimates are derived by each of the models, while precipitation comes from GPCC v6 with gauge correction factors from Fuchs et al. (2001). Each land pixel is an independent scatter point.

uct with gauge correction factors from Fuchs et al. (2001), to be consistent with Figs. 9 and 10. Overall, results are in agreement with the water balance scatterplots (Fig. 10). The fraction of precipitation that is evaporated $(E / P)$ is usually lower for PM-MOD; however, this does not happen due to an underestimation of the atmospheric demand for water, as the values of the ratio of potential evaporation over precipitation $\left(E_{\mathrm{p}} / P\right)$ are overall comparable to those from GLEAM and PT-JPL. The PM-MOD product, therefore, has a general tendency to overestimate the surface evaporative stress (i.e. underestimate the ratio of $E$ over $E_{\mathrm{p}}$ ), which may explain the overall lower estimates of evaporation found across our analyses. GLEAM and PT-JPL show a better fit to the Budyko diagram and a transition from arid to wet climates that is consistent with the average fluxes of precipitation and net radiation. Nevertheless, it is worth noting that all three models estimate average values of evaporation that overcome average precipitation in numerous areas.

\subsection{Partitioning of evaporation into separate components}

The flux of land evaporation results from the summation of three main components or sources: (a) transpiration (the process that describes the movement of water from the soil, through the plant xylem, to the leaf and finally to the atmosphere), (b) interception loss (the vaporization of the volume of water that is held by the surface of vegetation during rainfall), and (c) soil evaporation (the direct vaporization of water from the topsoil). These processes require separate consideration in models due to their differences in biophysical drivers and rates (Savenije, 2004; Dolman et al., 2014). In addition, two other contributors to evaporation are often considered separately: the direct evaporation (sublimation) from snowand ice-covered surfaces and the vaporization from continental water bodies (or open-water evaporation).

Transpiration is the component that has received the most attention from the scientific community in recent years, due to its connection to different biogeochemical cycles. The global contribution of transpiration to total average evaporation has been extensively debated recently (Schlesinger and
Jasechko, 2014; Wang et al., 2014). Studies have reported values ranging between 35 and $90 \%$, based on isotopes (Jasechko et al., 2013; Coenders-Gerrits et al., 2015), sapflow measurements (Moran et al., 2009), satellite data (Miralles et al., 2011a; Mu et al., 2011; Zhang et al., 2016), and modelling (Wang-Erlandsson et al., 2014). Consequently, this large range of uncertainty is also expected in the relative contribution from other evaporation sources. Moreover, reducing this uncertainty appears particularly challenging due to the limited amount of ground data that can be used for validation and the nature of the techniques used to measure latent heat flux: most measuring devices (e.g. lysimeters, eddycovariance instruments, scintillometers) cannot distinguish between the different sources of evaporation.

All three WACMOS-ET models estimate the components of evaporation separately. In the case of PT-JPL and PMMOD, the available energy is partitioned into the different land covers to estimate the contribution from each of them. The approach in GLEAM is somewhat different, as the flux of interception loss is calculated using a different algorithm than the one used for transpiration and soil evaporation. Figure 12 illustrates the average contribution of each evaporation component to the total flux as estimated by the WACMOS-ET models. In the case of GLEAM (which calculates sublimation separately), the flux from snow and ice has been added to the bare-soil evaporation in this figure to allow visual comparison to the other two products.

The discrepancy amongst modelled evaporation components shown in Fig. 12 is large and calls for a thorough validation of the way the contribution from different sources is estimated as well as perhaps an in-depth revision to ensure that the conceptual definition of these components is consistent from model to model. Regionally, disagreements are particularly large in transitional regimes; for instance, in the climatic gradient from the Congo rainforest to the savanna, the virtual total of the flux comes from transpiration in the case of GLEAM, while for PM-MOD direct soil evaporation is the dominant component. In tropical forests, the direct soil evaporation can also exceed transpiration in the case of PMMOD, while for GLEAM and PT-JPL bare-soil evaporation 
PM-MOD
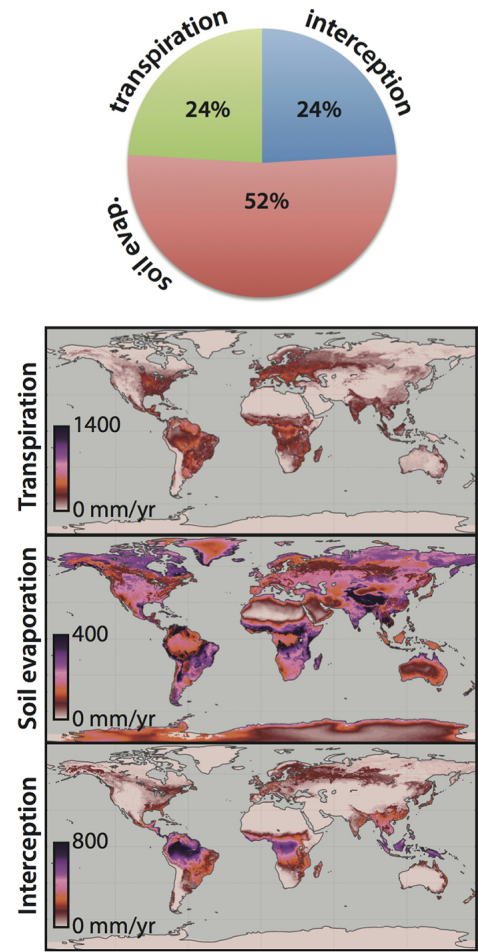

GLEAM
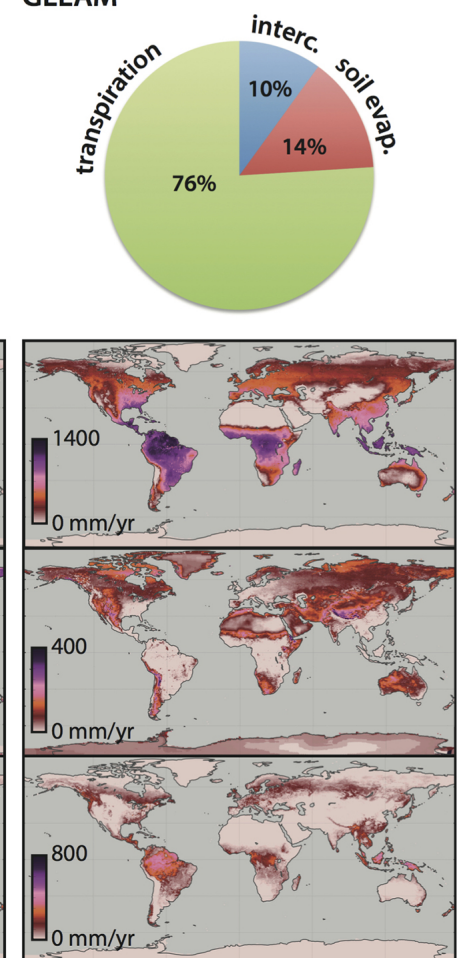

PT-JPL
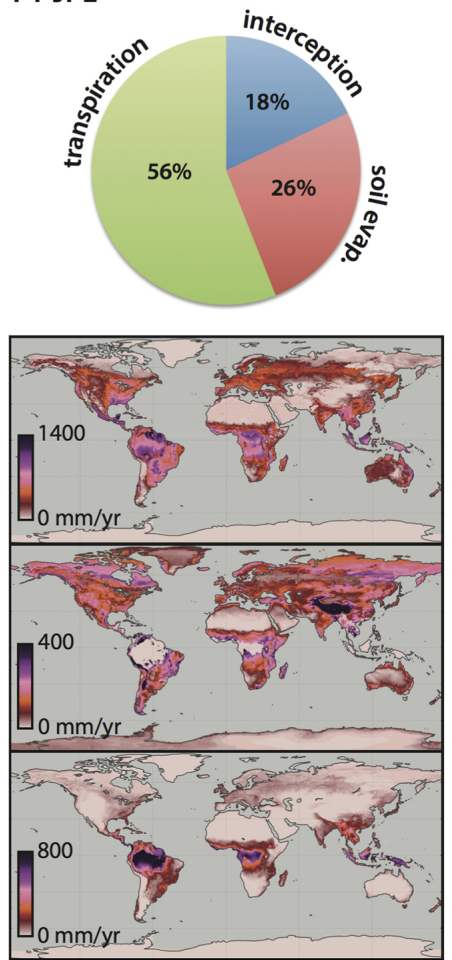

Figure 12. Partitioning evaporation. Maps indicate the average (2005-2007) transpiration, interception loss, and bare-soil evaporation for each of the three WACMOS-ET models. Pie diagrams illustrate the global average contribution to total land evaporation from each component and product.

is almost inexistent. The mean inter-model disagreement is manifest in the pie diagrams in Fig. 12, with GLEAM estimating a large contribution from transpiration $(76 \%)$ and a low contribution from soil evaporation (14\%), PM-MOD estimating little transpiration (24\%) and a large contribution from soil evaporation (52\%), and both PM-MOD and PT-JPL yielding a much larger flux of interception loss than GLEAM. Nevertheless, and as discussed above, recent reviews have revealed comparable levels of uncertainty in this partitioning based on a wide range of independent methods (see, e.g., Schlesinger and Jasechko, 2014; Wang et al., 2014).

While the global contribution of transpiration has received much attention in the literature (Jasechko et al., 2013; Coenders-Gerrits et al., 2015), the flux of interception loss has seldom been explored globally (Miralles et al., 2010; Vinukollu et al., 2011b; Wang-Erlandsson et al., 2014). The physical process of interception loss differs from that of transpiration on its sensitivity to environmental and climatic variables: the rates and magnitude of interception are dictated by the aerodynamic properties of the vegetation stand and the occurrence and characteristics of rainfall (Horton, 1919). In fact, while solar radiation is usually the main supply of energy for transpiration and soil evaporation (Wild and Liepert, 2010), the source of energy powering interception loss is still debated (Holwerda et al., 2011; van Dijk et al., 2015). This limited process understanding, together with the scarcity of ground measurements for validation, makes interception loss particularly challenging to model. Nonetheless, interception has often been reported in units of percentage of incoming rainfall during the restricted number of past in situ measuring campaigns; see, e.g., Miralles et al. (2010) for a nonexhaustive list of these campaigns. This makes interception measurements easy to extrapolate in time and space, and it allows for a relatively straightforward validation of the estimates from our three models. Therefore, Fig. 13 presents the daily time series of interception loss from PM-MOD, GLEAM, and PT-JPL for the average of the Amazon Basin (blue contour in Fig. 1), and it indicates the values reported by past campaigns in Amazonia. According to in situ measurements, there is a more than 2-fold overestimation of the mean flux in the case of PM-MOD and PT-JPL. Temporal dynamics of interception loss from the three products do not correlate well either, as GLEAM tends to follow the occurrence of rainfall, while PM-MOD and PT-JPL are more affected by net radiation variability, as expected from the interception algorithms (i.e. Gash's model for GLEAM, PenmanMonteith for PM-MOD, and Priestley and Taylor for PTJPL). 


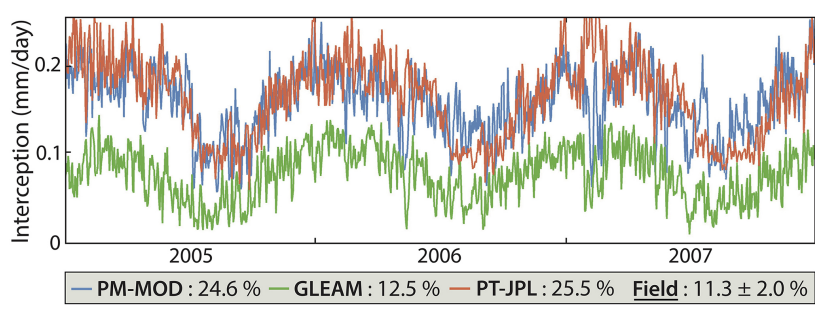

Figure 13. Interception loss in Amazonia. Daily time series of interception $\left(\mathrm{mm} \mathrm{day}^{-1}\right)$ for 2005-2007 from the three WACMOSET products as averaged for the entire Amazon Basin. The average interception (as percentage of rainfall) from the three models is listed, together with the mean ( $\pm 1 \mathrm{SD}-1$ standard deviation) of past field campaigns by Lloyd et al. (1988) ( \pm 1 SD), Czikowsky and Fitzjarrald (2009) (11.6\%), Ubarana (1996) (11.6\%), Cuartas et al. (2007) (13.3\%), Marin et al. (2000) (13.5\%), and Shuttleworth (1988) (9.1\%). See Fig. 1 for the Amazon catchment boundaries and the locations of the field measurements.

Further analyses are needed to explore the skill of these (and other) models to separately derive the different evaporation components or sources. Nevertheless, these preliminary analyses indicate the need for caution when using global estimates of transpiration, soil evaporation, or interception loss from a single model in isolation, as the disagreements can be much larger than for total land evaporation. To date, the lack of in situ networks that measure the components of evaporation independently remains an unsolved problem for the improvement of model estimates.

\section{Conclusions}

The ESA WACMOS-ET project started in 2012 with the goal of performing a cross comparison and validation exercise of a group of selected global observational evaporation algorithms driven by a consistent set of forcing data. With the project coming to an end, this article has focussed on the global and regional evaluation of the resulting evaporation data sets.

The three main models scrutinized here were the Penman-Monteith approach from the official MODIS evaporation product (Mu et al., 2007, 2011, 2013), GLEAM (Miralles et al., 2011b; Martens et al., 2016), and the PriestleyTaylor JPL (Fisher et al., 2008); the SEBS model (Su, 2002), which was analysed on the local scale in Part 1 (revealing good performance in terms of correlations but a systematic overestimation of evaporation), was not evaluated in this contribution. The spatiotemporal magnitude and variability of the resulting global evaporation products were compared to analogous estimates from reanalysis (ERA-Interim) and eddy-covariance-based global data (MTE). The representation of evaporation dynamics during droughts, the model skill to close the water balance over 837 river basins world- wide, and the partitioning of evaporation into different components have also been explored.

Despite our efforts to create a homogeneous forcing data set to run the evaporation models, the input requirements of each model are different, which implies that the resulting inter-product disagreements are the result of both internal differences in the models and uncertainties in forcing and ancillary data. This prevents us from making strong claims about the quality of the models. However, these analyses also provide the following take-home messages:

- In agreement with the local-scale validation in Part 1, the PM-MOD product tends to underestimate evaporation (see, e.g., Figs. 3 and 10). This underestimation is systematic, being larger in absolute terms in the tropics (where evaporation is larger) and larger in relative terms in drier subtropical regions (Fig. 3). As an exception, in high latitudes PM-MOD estimates are greater than those from GLEAM and PT-JPL; this may reflect known deficiencies in Priestley-Taylor-based approaches in conditions of low available energy (see, e.g., Parlange and Katul, 1992).

- The global average magnitudes of evaporation from GLEAM and PT-JPL agree well with each other and with the range of literature values (see Figs. 2 and 4). This agreement extends to the average latitudinal patterns, which lie between those of PM-MOD and ERAInterim (Figs. 2 and 3). In terms of temporal dynamics, there are differences between GLEAM and PTJPL in dry conditions, as expected from their distinctive approach to representing evaporative stress (see Sect. 2.1). These differences are pronounced in the Southern Hemisphere subtropics (Fig. 6a), reflected more clearly in daily anomalies than in seasonal cycles (Fig. 8), and may be exacerbated during specific drought events (Fig. 9).

- The partitioning of evaporation into different components is a facet of these models that has not received enough attention in previous applications. Each model has a distinct way to estimate these components, and even in cases in which inter-product average evaporation agrees, the separate contribution from these components may fluctuate substantially (Fig. 12). As an example, differences in interception loss amongst models (Fig. 13) may explain a large part of the disagreements in the seasonality of evaporation over tropical forests (Fig. 8). Further exploring the skill of these models at partitioning evaporation into its different sources remains a critical task for the future. This is outside the scope of WACMOS-ET, and it would require innovative means of validation beyond traditional comparisons to eddy-covariance and lysimeter data. 
- On a more positive note, the analysis of the skill of different models to close the water balance over particular catchments reveals that the general climatic patterns of evaporation are well captured by all models (Fig. 10). While this comparison has also unveiled the general underestimation by PM-MOD (and overestimation by ERA-Interim), all products correlate well with the cumulative values of $P-Q$. We stress, however, that this agreement does not indicate whether the multi-scale temporal dynamics of evaporation are well captured. For a thorough validation of evaporation temporal variability, we direct the readers to Part 1.

In summary, the activities in WACMOS-ET have demonstrated that some of the existing evaporation models require an in-depth scrutiny to correct for systematic errors in their estimates. This is especially the case over semi-arid regions and tropical forests. In addition, even models that have demonstrated a more robust performance, like GLEAM and PT-JPL, may differ substantially from one another given certain biomes and climates. Overall, our results imply the need for caution in using a single model for any large-scale application in isolation, especially in studies in which transpiration, soil evaporation, or interception loss are investigated separately.

As remote sensing science continues to advance, new long-term records of physical variables to constrain these models are becoming available (e.g. chlorophyll fluorescence, surface soil moisture). While further tools to improve evaporation models become accessible, the possibility of considering biome- or climate-specific composites of flux algorithms is currently being explored, given the general finding that different models may perform better under certain conditions (Ershadi et al., 2014; McCabe et al., 2016). For an inter-product merger to add new skill, the sensitivity of each model to its forcing should be further explored, and a robust propagation of uncertainties appears essential to merge these products efficiently.

The reader is directed to additional supporting documents available form the project website at http://WACMOS-ET. estellus.eu.

Author contributions. D. G. Miralles, C. Jiménez, M. Jung, D. Michel, A. Ershadi, M. F. McCabe, M. Hirschi, and D. Fernández-Prieto designed the content of the manuscript. D. G. Miralles, C. Jiménez, and M. Jung did the analyses. D. G. Miralles wrote the paper. J. B. Fisher and Q. Mu provided the computer codes of the PT-JPL and PM-MOD models, respectively. All authors contributed to carrying out the project and to the discussion and interpretation of results.

Acknowledgements. This work was undertaken as part of the European Space Agency (ESA) project WACMOS-ET (Contract No. 4000106711/12/I-NB). Discharge data were provided by the
Global Runoff Data Centre, 56068 Koblenz, Germany. We thank Ulrich Weber and Eric Thomas for processing the catchment data. D. G. Miralles acknowledges the financial support from The Netherlands Organization for Scientific Research through grant 863.14.004, and the Belgian Science Policy Office (BELSPO) in the framework of the STEREO III programme, project SAT-EX (SR/00/306). A. Ershadi and M. F. McCabe acknowledge funding from the King Abdullah University of Science and Technology. J. B. Fisher acknowledges funding under the NASA Terrestrial Hydrology Program.

Edited by: P. Gentine

\section{References}

Baldocchi, D., Falge, E., Gu, L., Olson, R., Hollinger, D., Running, S., Anthoni, P., Bernhofer, C., Davis, K., Evans, R., Fuentes, J., Goldstein, A., Katul, G., Law, B., Lee, X., Malhi, Y., Meyers, T., Munger, W., Oechel, W., Paw, K. T., Pilegaard, K., Schmid, H. P., Valentini, R., Verma, S., Vesala, T., Wilson, K., and Wofsy, S.: FLUXNET: A new tool to study the temporal and spatial variability of ecosystem-scale carbon dioxide, water vapor, and energy flux densities, B. Am. Meteorol. Soc., 82, 2415-2434, 2001.

Baumgartner, A. and Reichel, E.: The World Water Balance: Mean Annual Global Continental and Maritime Precipitation, Evaporation and Runoff, Elsevier Scientific Publishing Company, Amsterdam, the Netherlands, Oxford, UK, New York, USA, 1975.

Budyko, M. I.: Climate and life, International Geophysics Series, Academic Press, New York, 1974.

Chen, M., Shi, W., Xie, P., Silva, V. B. S., Kousky, V. E., Wayne Higgins, R., and Janowiak, J. E.: Assessing objective techniques for gauge-based analyses of global daily precipitation, J. Geophys. Res., 113, D04110, doi:10.1029/2007JD009132, 2008.

Chen, X. and Hu, Q.: Groundwater influences on soil moisture and surface evaporation, J. Hydrol., 297, 285-300, doi:10.1016/j.jhydrol.2004.04.019, 2004.

Chen, Y., Xia, J., Liang, S., Feng, J., Fisher, J. B., Li, X., Li, X., Liu, S., Ma, Z., Miyata, A., Mu, Q., Sun, L., Tang, J., Wang, K., Wen, J., Xue, Y., Yu, G., Zha, T., Zhang, L., Zhang, Q., Zhao, T., Zhao, L., Zhou, G., and Yuan, W.: Comparison of satellite-based evapotranspiration models over terrestrial ecosystems in China, Remote Sens. Environ., 140, 279-293, 2014.

Cleugh, H. A., Leuning, R., Mu, Q., and Running, S. W.: Regional evaporation estimates from flux tower and MODIS satellite data, Remote Sens. Environ., 106, 285-304, doi:10.1016/j.rse.2006.07.007, 2007.

Coccia, G., Siemann, A., Pan, M., and Wood, E. F.: Creating consistent datasets by combining remotely-sensed data and land surface model estimates through Bayesian uncertainty post-processing: the case of Land Surface Temperature from HIRS, Remote Sens. Environ., 170, 290-305, doi:10.1016/j.rse.2015.09.010, 2015.

Coenders-Gerrits, A. M. J., van der Ent, R. J., Bogaard, T. A., Wang-Erlandsson, L., Hrachowitz, M., and Savenije, H. H. G.: Uncertainties in transpiration estimates, Nature, 506, E1-E2, doi:10.1038/nature12925, 2015.

Cuartas, L., Tomasella, J., Nobre, A., Hodnett, M., Waterloo, M., and Múnera, J.: Interception water-partitioning dynamics for a pristine rainforest in Central Amazonia: marked differences be- 
tween normal and dry years, Agr. Forest Meteorol., 145, 69-83, 2007.

Czikowsky, M. and Fitzjarrald, D.: Detecting rainfall interception in an Amazonian rain forest with eddy flux measurements, J. Hydrol., 377, 92-105, 2009.

Dalton, J.: On evaporation, Essay III, in: Experimental essays on the 121 constitution of mixed gases; on the force of steam or vapour from water or other liquids in different temperatures; both in a Torrecellian vacuum and in air; on evaporation; and on the expansion of gases by heat, Mem. Proc. Lit. Phil. Soc. Manchester, 5, 574-594, 1802.

Dee, D. P., Uppala, S. M., Simmons, A. J., Berrisford, P., Poli, P., Kobayashi, S., Andrae, U., Balmaseda, M. A., Balsamo, G., Bauer, P., Bechtold, P., Beljaars, A. C. M., van de Berg, L., Bidlot, J., Bormann, N., Delsol, C., Dragani, R., Fuentes, M., Geer, A. J., Haimberger, L., Healy, S. B., Hersbach, H., Hólm, E. V., Isaksen, L., Kållberg, P., Köhler, M., Matricardi, M., McNally, A. P., Monge-Sanz, B. M., Morcrette, J. J., Park, B. K., Peubey, C., De Rosnay, P., Tavolato, C., Thépaut, J. N., and Vitart, F.: The ERA-Interim reanalysis: configuration and performance of the data assimilation system, Q. J. Roy. Meteorol. Soc., 137, 553597, 2011.

Di Baldassarre, G. and Montanari, A.: Uncertainty in river discharge observations: a quantitative analysis, Hydrol. Earth Syst. Sci., 13, 913-921, doi:10.5194/hess-13-913-2009, 2009.

Dolman, A. J., Miralles, D. G., and De Jeu, R. A. M.: Fifty years since Monteith's 1965 seminal paper: the emergence of global ecohydrology, Ecohydrology, 7, 897-902, doi:10.1002/eco.1505, 2014.

Douville, H., Ribes, A., Decharme, B., Alkama, R., and Sheffield, J.: Anthropogenic influence on multidecadal changes in reconstructed global evapotranspiration, Nat. Clim. Change, 3, 59-62, 2013.

Ershadi, A., McCabe, M. F., Evans, J. P., Chaney, N. W., and Wood, E. F.: Multi-site evaluation of terrestrial evaporation models using FLUXNET data, Agr. Forest Meteorol., 187, 46-61, doi:10.1016/j.agrformet.2013.11.008, 2014.

Fisher, J. B., Tu, K. P., and Baldocchi, D. D.: Global estimates of the land-atmosphere water flux based on monthly AVHRR and ISLSCP-II data, validated at 16 FLUXNET sites, Remote Sens. Environ., 112, 901-919, 2008.

Fuchs, T., Rapp, J., Rubel, F., and Rudolf, B.: Correction of synoptic precipitation observations due to systematic measuring errors with special regard to precipitation phases, Phys. Chem. Earth, 26, 689-693, 2001.

Gash, J. H.: An analytical model of rainfall interception by forests, Q. J. Roy. Meteorol. Soc., 105, 43-45, 1979.

Guillod, B. P., Orlowsky, B., Miralles, D. G., Teuling, A. J., and Seneviratne, S. I.: Reconciling spatial and temporal soil moisture effects on afternoon rainfall, Nat. Commun., 6, 1-6, doi:10.1038/ncomms7443, 2015.

Hagemann, S., Chen, C., Clark, D. B., Folwell, S., Gosling, S. N., Haddeland, I., Hanasaki, N., Heinke, J., Ludwig, F., Voss, F., and Wiltshire, A. J.: Climate change impact on available water resources obtained using multiple global climate and hydrology models, Earth Syst. Dynam., 4, 129-144, doi:10.5194/esd4-129-2013, 2013.

Holwerda, F., Bruijnzeel, L. A., Scatena, F. N., Vugts, H. F., and Meesters, A. G. C. A.: Wet canopy evaporation from a Puerto
Rican lower montane rain forest: The importance of realistically estimated aerodynamic conductance, J. Hydrol., 414-415, 1-15, doi:10.1016/j.jhydrol.2011.07.033, 2011.

Horton, R. E.: Rainfall interception, Mon. Weather Rev., 47, 603$625,1919$.

Huffman, G. J., Adler, R. F., Morrissey, M., Bolvin, D. T., Curtis, S., Joyce, R., McGavock, B., and Susskind, J.: Global precipitation at one-degree daily resolution from multi-satellite observations, J. Hydrometeorol., 2, 36-50, 2001.

Jarvis, P. G.: The interpretation of the variations in leaf water potential and stomatal conductance found in canopies in the field, Philos. T. Roy. Soc. Lond., 273, 593-610, 1976.

Jasechko, S., Sharp, Z. D., Gibson, J. J., Birks, S. J., Yi, Y., and Fawcett, P. J.: Terrestrial water fluxes dominated by transpiration, Nature, 496, 347-350, 2013.

Jiménez, C., Prigent, C., Mueller, B., Seneviratne, S. I., McCabe, M. F., Wood, E. F., Rossow, W. B., Balsamo, G., Betts, A. K., Dirmeyer, P. A., Fisher, J. B., Jung, M., Kanamitsu, M., Reichle, R. H., Reichstein, M., Rodell, M., Sheffield, J., $\mathrm{Tu}, \mathrm{K}$., and Wang, K.: Global intercomparison of 12 land surface heat flux estimates, J. Geophys. Res., 116, D02102, doi:10.1029/2010JD014545, 2011.

Jung, M., Reichstein, M., and Bondeau, A.: Towards global empirical upscaling of FLUXNET eddy covariance observations: validation of a model tree ensemble approach using a biosphere model, Biogeosciences, 6, 2001-2013, doi:10.5194/bg-6-20012009, 2009.

Jung, M., Reichstein, M., Ciais, P., Seneviratne, S. I., Sheffield, J., Goulden, M. L., Bonan, G., Cescatti, A., Chen, J., and de Jeu, R.: Recent decline in the global land evapotranspiration trend due to limited moisture supply, Nature, 467, 951-954, 2010.

Kalma, J., McVicar, T., and McCabe, M.: Estimating Land Surface Evaporation: A Review of Methods Using Remotely Sensed Surface Temperature Data, Surv. Geophys., 29, 421-469, 2008.

Kelly, R. E., Chang, A. T., Tsang, L., and Foster, J. L.: A prototype AMSR-E global snow area and snow depth algorithm, IEEE T. Geosci. Remote, 41, 230-242, 2003.

Koster, R. D., Sud, Y., Guo, Z., Dirmeyer, P. A., Bonan, G., Oleson, K. W., Chan, E., Verseghy, D., Cox, P., and Davies, H.: GLACE: the global land-atmosphere coupling experiment. Part I: overview, J. Hydrometeorol., 7, 590-610, 2006.

Leblanc, M., Tweed, S., Van Dijk, A., and Timbal, B.: A review of historic and future hydrological changes in the Murray-Darling Basin, Global Planet. Change, 80-81, 226-246, doi:10.1016/j.gloplacha.2011.10.012, 2012.

Legates, D. R. and Willmott, C. J.: Mean seasonal and spatial variability in gauge-corrected, global precipitation, Int. J. Climatol., 10, 111-127, doi:10.1002/joc.3370100202, 1990.

Liu, Y., Zhuang, Q., Pan, Z., Miralles, D., Tchebakova, N., Kicklighter, D., Chen, J., Sirin, A., He, Y., Zhou, G., and Melillo, J.: Response of evapotranspiration and water availability to the changing climate in Northern Eurasia, Climatic Change, 126, 413-427, doi:10.1007/s10584-014-1234-9, 2014.

Liu, Y. Y., de Jeu, R. A. M., McCabe, M. F., Evans, J. P., and van Dijk, A. I. J. M.: Global long-term passive microwave satellitebased retrievals of vegetation optical depth, Geophys. Res. Lett., 38, L18402, doi:10.1029/2011GL048684, 2011.

Liu, Y. Y., Dorigo, W. A., Parinussa, R. M., De Jeu, R. A. M., Wagner, W., Mccabe, M. F., Evans, J. P., and Van Dijk, A. I. J. M.: 
Trend-preserving blending of passive and active microwave soil moisture retrievals, Remote Sens. Environ., 123, 1-18, 2012.

Lloyd, C. R., Gash, J. H. C., Shuttleworth, W. J. and de Marques, F. A. O.: The measurement and modelling of rainfall interception by Amazonian rain forest, Agr. Forest Meteorol., 43, 277-294, 1988.

Luojus, K. and Pulliainen, J.: Global snow monitoring for climate research: Snow Water Equivalent (SWE) product guide, Helsinki, Finland, http://www.globsnow.info/swe/GlobSnow_ SWE_product_readme_v1.0a.pdf (last access: February 2016), 2010.

Marin, C., Bouten, W., and Sevink, J.: Gross rainfall and its partitioning into throughfall, stemflow and evaporation of intercepted water in four forest ecosystems in western Amazonia, J. Hydrol., 237, 40-57, 2000.

Martens, B., Miralles, D. G., Verhoest, N. E. C., Lievens, H., and Fernandez-Prieto, D.: Improving terrestrial evaporation estimates over continental Australia through assimilation of SMOS soil moisture, Int. J. Appl. Earth Obs., doi:10.1016/j.jag.2015.09.012, in press, 2016.

McCabe, M. F., Miralles, D. G., Jiménez, C., Ershadi, A., Fisher, J. B., Mu, Q., Liang, M., Mueller, B., Sheffield, J., Seneviratne, S. I., and Wood, E. F.: Global scale estimation of land surface heat fluxes from space: product assessment and intercomparison, in: Remote Sensing of Energy fluxes and Soil Moisture Content, edited by: Petropoulos, G., Taylor and Francis, CRC Press, Boca Raton, FL, 249-282, doi:10.1201/b15610-13, 2013.

McCabe, M. F., Ershadi, A., Jiménez, C., Miralles, D. G., Michel, D., and Wood, E. F.: The GEWEX LandFlux project: evaluation of model evaporation using tower-based and globally-gridded forcing data, Geosci. Model Dev., 9, 283-305, doi:10.5194/gmd9-283-2016, 2016.

Michel, D., Jiménez, C., Miralles, D. G., Jung, M., Hirschi, M., Ershadi, A., Martens, B., McCabe, M. F., Fisher, J. B., Mu, Q., Seneviratne, S. I., Wood, E. F., and Fernández-Prieto, D.: The WACMOS-ET project - Part 1: Tower-scale evaluation of four remote sensing-based evapotranspiration algorithms, Hydrol. Earth Syst. Sci., 20, 803-822, doi:10.5194/hess-20-8032016, 2016.

Miralles, D. G., Gash, J. H., Holmes, T. R. H., de Jeu, R. A. M., and Dolman, A.: Global canopy interception from satellite observations, J. Geophys. Res., 115, D16122, doi:10.1029/2009JD013530, 2010.

Miralles, D. G., De Jeu, R. A. M., Gash, J. H., Holmes, T. R. H., and Dolman, A. J.: Magnitude and variability of land evaporation and its components at the global scale, Hydrol. Earth Syst. Sci., 15, 967-981, doi:10.5194/hess-15-967-2011, 2011a.

Miralles, D. G., Holmes, T. R. H., De Jeu, R. A. M., Gash, J. H., Meesters, A. G. C. A., and Dolman, A. J.: Global land-surface evaporation estimated from satellite-based observations, Hydrol. Earth Syst. Sci., 15, 453-469, doi:10.5194/hess-15-453-2011, 2011b.

Miralles, D. G., Teuling, A. J., van Heerwaarden, C. C., and VilàGuerau de Arellano, J.: Mega-heatwave temperatures due to combined soil desiccation and atmospheric heat accumulation, Nat. Geosci., 7, 345-349, doi:10.1038/ngeo2141, 2014a.

Miralles, D. G., van den Berg, M. J., Gash, J. H., Parinussa, R. M., De Jeu, R. A. M., Beck, H. E., Holmes, T. R. H., Jiménez, C., Verhoest, N. E. C., Dorigo, W. A., Teuling, A. J., and Dolman,
A. J.: El Niño-La Niña cycle and recent trends in continental evaporation, Nat. Clim. Change, 4, 122-126, 2014 b.

Monteith, J. L.: Evaporation and environment, Symposia of the Society for Exp. Biol., 19, 205-234, 1965.

Moran, M. S., Scott, R. L., Keefer, T. O., and Emmerich, W. E.: Partitioning evapotranspiration in semiarid grassland and shrubland ecosystems using time series of soil surface temperature, Agr. Forest Meteorol., 149, 59-72, doi:10.1016/j.agrformet.2008.07.004, 2009.

Mu, Q., Heinsch, F. A., Zhao, M., and Running, S. W.: Development of a global evapotranspiration algorithm based on MODIS and global meteorology data, Remote Sens. Environ., 111, 519-536, doi:10.1016/j.rse.2007.04.015, 2007.

Mu, Q., Zhao, M., and Running, S. W.: Improvements to a MODIS global terrestrial evapotranspiration algorithm, Remote Sens. Environ., 115, 1781-1800, 2011.

Mu, Q., Zhao, M., and Running, S. W.: MODIS Global Terrestrial Evapotranspiration (ET) Product (NASA MOD16A2/A3), Algorithm Theoretical Basis Document, Collection 5, NASA HQ, Numerical Terradynamic Simulation Group, University of Montana, Missoula, MT, USA, 20 November 2013.

Mueller, B., Seneviratne, S. I., Jiménez, C., Corti, T., Hirschi, M., Balsamo, G., Ciais, P., Dirmeyer, P., Fisher, J. B., Guo, Z., Jung, M., Maignan, F., McCabe, M. F., Reichle, R., Reichstein, M., Rodell, M., Sheffield, J., Teuling, A. J., Wang, K., Wood, E. F., and Zhang, Y.: Evaluation of global observations-based evapotranspiration datasets and IPCC AR4 simulations, Geophys. Res. Lett., 38, L06402, doi:10.1029/2010GL046230, 2011.

Mueller, B., Hirschi, M., Jiménez, C., Ciais, P., Dirmeyer, P. A., Dolman, A. J., Fisher, J. B., Jung, M., Ludwig, F., Maignan, F., Miralles, D., McCabe, M. F., Reichstein, M., Sheffield, J., Wang, K. C., Wood, E. F., Zhang, Y., and Seneviratne, S. I.: Benchmark products for land evapotranspiration: LandFluxEVAL multi-dataset synthesis, Hydrol. Earth Syst. Sci., 17, 3707-3720, doi:10.5194/hess-17-3707-2013, 2013.

Murphy, D. and Koop, T.: Review of the vapour pressures of ice and supercooled water for atmospheric applications, Q. J. Roy. Meteorol. Soc., 131, 1539-1565, 2005.

Oki, T. and Kanae, S.: Global hydrological cycles and world water resources, Science, 313, 1068-1072, doi:10.1126/science.1128845, 2006.

Orellana, F., Verma, P., Loheide, I. I. S. P., and Daly, E.: Monitoring and modeling water-vegetation interactions in groundwater-dependent ecosystems, Rev. Geophys., 50, RG3003, doi:10.1029/2011RG000383, 2012.

Parlange, M. B. and Katul, G. G.: An advection-aridity evaporation model, Water Resour. Res., 28, 127-132, doi:10.1029/91wr02482, 1992.

Penman, H. L.: Natural evaporation from open water, bare soil and grass, P. Roy. Soc. Lond. A, 193, 120-145, 1948.

Priestley, C. and Taylor, R.: On the assessment of surface heat flux and evaporation using large-scale parameters, Mon. Weather Rev., 100, 81-92, 1972.

Reichstein, M., Bahn, M., Ciais, P., Frank, D., Mahecha, M. D., Seneviratne, S. I., Zscheischler, J., Beer, C., Buchmann, N., Frank, D. C., Papale, D., Rammig, A., Smith, P., Thonicke, K., van der Velde, M., Vicca, S., Walz, A., and Wattenbach, M.: Climate extremes and the carbon cycle, Nature, 500, 287-295, doi:10.1038/nature12350, 2013. 
Saha, S., Moorthi, S., Pan, H.-L., Wu, X., Wang, J., Nadiga, S., Tripp, P., Kistler, R., Woollen, J., Behringer, D., Liu, H., Stokes, D., Grumbine, R., Gayno, G., Wang, J., Hou, Y.-T., Chuang, H.Y., Juang, H.-M. H., Sela, J., Iredell, M., Treadon, R., Kleist, D., Van Delst, P., Keyser, D., Derber, J., Ek, M., Meng, J., Wei, H., Yang, R., Lord, S., Van Den Dool, H., Kumar, A., Wang, W., Long, C., Chelliah, M., Xue, Y., Huang, B., Schemm, J.-K., Ebisuzaki, W., Lin, R., Xie, P., Chen, M., Zhou, S., Higgins, W., Zou, C.-Z., Liu, Q., Chen, Y., Han, Y., Cucurull, L., Reynolds, R. W., Rutledge, G., and Goldberg, M.: The NCEP Climate Forecast System Reanalysis, B. Am. Meteorol. Soc., 91, 1015-1057, doi:10.1175/2010BAMS3001.2, 2010.

Sahoo, A. K., Pan, M., Troy, T. J., Vinukollu, R. K., Sheffield, J., and Wood, E. F.: Reconciling the global terrestrial water budget using satellite remote sensing, Remote Sens. Environ., 115, 1850-1865, 2011.

Savenije, H. G.: The importance of interception and why we should delete the term evapotranspiration from our vocabulary, Hydrol. Process. 18, 1507-1511, doi:10.1002/hyp.5563, 2004.

Schlesinger, W. H. and Jasechko, S.: Transpiration in the global water cycle, Agr. Forest Meteorol., 189-190, 115-117, doi:10.1016/j.agrformet.2014.01.011, 2014.

Schlosser, C. A. and Gao, X.: Assessing evapotranspiration estimates from the second Global Soil Wetness Project (GSWP-2) simulation, J. Hydrometeorol., 11, 880897, doi:10.1175/2010JHM1203.1, 2010.

Schneider, U., Becker, A., Finger, P., Meyer-Christoffer, A., Ziese, M., and Rudolf, B.: GPCC's new land surface precipitation climatology based on quality-controlled in situ data and its role in quantifying the global water cycle, Theor. Appl. Climatol., 115, 15-40, doi:10.1007/s00704-013-0860-x, 2013.

Seneviratne, S. I., Lüthi, D., Litschi, M., and Schär, C.: Landatmosphere coupling and climate change in Europe, Nature, 443, 205-209, 2006.

Seneviratne, S. I., Corti, T., Davin, E. L., Hirschi, M., Jaeger, E. B., Lehner, I., Orlowsky, B., and Teuling, A. J.: Investigating soil moisture-climate interactions in a changing climate: A review, Earth Sci. Rev., 99, 125-161, 2010.

Sheffield, J., Wood, E. F., and Roderick, M. L.: Little change in global drought over the past 60 years, Nature, 491, 435-438, 2012.

Shuttleworth, W. J.: Evaporation from the Amazonian rainforest, Philos. T. Roy. Soc. Lond., 233, 321-346, 1988.

Stackhouse, P. W., Gupta, S. K., Cox, S. J., Mikovitz, J. C., Zhang, T., and Chiacchio, M.: 12-year surface radiation budget dataset, GEWEX News, 14, 10-12, 2004.

$\mathrm{Su}, \mathrm{Z}$. : The Surface Energy Balance System (SEBS) for estimation of turbulent heat fluxes, Hydrol. Earth Syst. Sci., 6, 85-100, doi:10.5194/hess-6-85-2002, 2002.

Su, Z., Dorigo, W., Fernández-Prieto, D., Van Helvoirt, M., Hungershoefer, K., de Jeu, R., Parinussa, R., Timmermans, J., Roebeling, R., Schröder, M., Schulz, J., Van der Tol, C., Stammes, P., Wagner, W., Wang, L., Wang, P., and Wolters, E.: Earth observation Water Cycle Multi-Mission Observation Strategy (WACMOS), Hydrol. Earth Syst. Sci. Discuss., 7, 78997956, doi:10.5194/hessd-7-7899-2010, 2010.

Su, Z., Roebeling, R., Schulz, J., Holleman, I., Levizzani, V., Timmermans, W., Rott, H., Mognard-Campbell, N., De Jeu, R., and Wagner, W.: Observation of Hydrological Processes Using Re- mote Sensing, Treatise on Water Science, edited by: Wilderer, P., Academic Press, Oxford, 2, 351-399, 2011.

Teuling, A. J., Van Loon, A. F., Seneviratne, S. I., Lehner, I., Aubinet, M., Heinesch, B., Bernhofer, C., Grünwald, T., Prasse, H., and Spank, U.: Evapotranspiration amplifies European summer drought, Geophys. Res. Lett., 40, 2071-2075, doi:10.1002/grl.50495, 2013.

Ubarana, V.: Observations and modelling of rainfall interception at two experimental sites in Amazonia, in: Amazonian Deforestation and Climate, edited by: Gash, J. H. C., Nobre, C. A., Robert, J. M., and Victoria, R. L., John Wiley, Chichester, UK, 151-162, 1996.

van Dijk, A. I. J. M., Beck, H. E., Crosbie, R. S., De Jeu, R. A. M., Liu, Y. Y., Podger, G. M., Timbal, B., and Viney, N. R.: The Millennium Drought in southeast Australia (2001-2009): Natural and human causes and implications for water resources, ecosystems, economy, and society, Water Resour. Res., 49, 1040-1057, doi:10.1002/wrcr.20123, 2013.

van Dijk, A. I. J. M., Gash, J. H., van Gorsel, E., Blanken, P. D., Cescatti, A., Emmel, C., Gielen, B., Harman, I., Kiely, G., Merbold, L., Montagnani, L., Moors, E., Roland, M., Sottocornola, M., Varlagin, A., Williams, C. A., and Wohlfahrt, G.: Rainfall interception and the coupled surface water and energy balance, Agr. Forest Meteorol., 214-215, 402-415, doi:10.1016/j.agrformet.2015.09.006, 2015.

Vinukollu, R. K., Meynadier, R., Sheffield, J., and Wood, E. F.: Multi-model, multi-sensor estimates of global evapotranspiration: climatology, uncertainties and trends, Hydrol. Process., 25, 3993-4010, doi:10.1002/hyp.8393, 2011a.

Vinukollu, R. K., Wood, E. F., Ferguson, C. R., and Fisher, J. B.: Global estimates of evapotranspiration for climate studies using multi-sensor remote sensing data: Evaluation of three process-based approaches, Remote Sens. Environ., 115, 801823, doi:10.1016/j.rse.2010.11.006, 2011 b.

Wang, K. and Dickinson, R. E.: A review of global terrestrial evapotranspiration: Observation, modeling, climatology, and climatic variability, Rev. Geophys., 50, RG2005, doi:10.1029/2011RG000373, 2012.

Wang, L., Good, S. P., and Caylor, K. K.: Global synthesis of vegetation control on evapotranspiration partitioning, Geophys. Res. Lett., 41, 6753-6757, doi:10.1002/(ISSN)1944-8007, 2014.

Wang-Erlandsson, L., van der Ent, R. J., Gordon, L. J., and Savenije, H. H. G.: Contrasting roles of interception and transpiration in the hydrological cycle - Part 1: Temporal characteristics over land, Earth Syst. Dynam., 5, 441-469, doi:10.5194/esd-5-4412014, 2014.

Wielicki, B. A., Barkstrom, B. R., Harrison, E. F., Lee Iii, R. B., Louis Smith, G., and Cooper, J. E.: Clouds and the Earth's Radiant Energy System (CERES): An earth observing system experiment, B. Am. Meteorol. Soc., 77, 853-868, 2000.

Wild, M. and Liepert, B.: The Earth radiation balance as driver of the global hydrological cycle, Environ. Res. Lett., 5, 025203, doi:10.1088/1748-9326/5/2/025003, 2010.

Wild, M., Folini, D., Hakuba, M. Z., Schar, C., Seneviratne, S. I., Kato, S., Rutan, D., Ammann, C., Wood, E. F., and KönigLanglo, G.: The energy balance over land and oceans: an assessment based on direct observations and CMIP5 climate models, Clim. Dynam., 44, 3393-3429, doi:10.1007/s00382-014-2430-z, 2014. 
Zhang, K., Kimball, J. S., Nemani, R. R., and Running, S. W.: A continuous satellite-derived global record of land surface evapotranspiration from 1983 to 2006, Water Resour. Res., 46, W09522, doi:10.1029/2009WR008800, 2010.

Zhang, K., Kimball, J. S., Nemani, R. R., Running, S. W., Hong, Y., Gourley, J. J., and Yu, Z.: Vegetation greening and climate change promote multidecadal rises of global land evapotranspiration, Sci. Rep., 5, 15956, doi:10.1038/srep15956, 2015.
Zhang, Y., Peña-Arancibia, J. L., McVicar, T. R., Chiew, F. H. S., Vaze, J., Liu, C., Lu, X., Zheng, H., Wang., Y., Liu, Y. Y., Miralles, D. M., and Pan, M.: Multi-decadal trends in global terrestrial evapotranspiration and its components, Sci. Rep., 5, 19124, doi:10.1038/srep19124, 2016. 